\title{
The visual search analogue of latent inhibition: Implications for theories of irrelevant stimulus processing in normal and schizophrenic groups
}

\author{
R. E. LUBOW \\ Tel Aviv University, Ramat Aviv, Israel \\ and \\ OREN KAPLAN \\ College of Management, Rishon Lezion, Israel
}

\begin{abstract}
Latent inhibition (LI) is a robust phenomenon that is demonstrated when a previously inconsequential stimulus is less effective in a new learning situation than a novel stimulus. Despite LI's simplicity, there is considerable disagreement as to its theoretical basis. Attentional theories claim that unattended stimulus preexposures reduce stimulus associability. Alternatively, it has been asserted that associability is unaffected and that LI is a result of competition/retrieval processes. The present article reviews a series of visual search studies, some with normal subjects, both undifferentiated and divided into low and high schizotypals, and others with pathologies that entail dysfunctional attention, such as schizophrenia, Parkinson's disease, and anxiety. The visual search conditions were designed to model those of traditional LI experiments, while tapping attentional processes independently of the learning scores that index LI. A variety of evidence from these and other studies is used to support the involvement of attentional and retrieval processes in LI. A model of the mechanism of action of these processes in LI is presented, together with its application to schizophrenia.
\end{abstract}

There are some conditions that make it more difficult to acquire or to express a new association to a familiar stimulus than one to a novel stimulus, particularly when the familiar stimulus has been previously unattended. This situation is expressed in an apparently simple phenomenon, called latent inhibition (LI). LI occurs across a variety of species, including pigeons, rats, and humans, and in many different testing paradigms, from simple classical conditioning to rule learning (for a review, see Lubow, 1989). Given the generality and robustness of this stimulus preexposure effect, it is not surprising to find that LI has a significant place in the history of psychological research, beginning with issues in classical learning theory (for reviews, see Hall, 1991; Lubow, 1989) and extending through the study of the processing of irrelevant information associated with high schizotypality and schizophrenia (for reviews, see Braunstein-Bercovitz, Rammsayer, Gibbons, \& Lubow, 2002; Escobar, Oberling, \& Miller, 2002; Lubow, 2005; Lubow \& Gewirtz, 1995) and even of creativity (Carson, Peterson, \& Higgins, 2003).

Despite the overwhelming evidence that preexposure to a stimulus may have a negative impact on the demonstration of subsequent learning with that stimulus, ex-

Preparation of this article was supported by a grant from the Israel Science Foundation, funded by the Israel Academy of Sciences and $\mathrm{Hu}-$ manities. Correspondence concerning this article should be addressed to R. E. Lubow, Department of Psychology, Tel Aviv University, Ramat Aviv 69978, Israel (e-mail: lubow@freud.tau.ac.il). tensive documentation indicates that such stimulus preexposure may also enhance performance on a learning task, as in perceptual-learning effects (for reviews, see Gibson, 1969; Hall, 1991). Whether one obtains poorer or better learning following stimulus preexposure depends on the conditions of stimulus preexposure, the relationship between the preexposure and the test contexts, including the time between them and where that time is spent, and the choice of a comparison (control) group. Briefly, LI in humans is favored when (1) the preexposed stimulus is not relevant to (is unattended in) the preexposure task (masking task) but is relevant to the test task. (2) the preexposure and test contexts are the same, and (3) the stimulus-preexposed (PE) group is compared with a group that is not preexposed (NPE) to the to-betarget stimulus but has spent the same amount of time in the preexposure context. In opposition to LI, perceptual learning is promoted when (1) the preexposed stimulus is relevant to (attended in) the preexposure task and continues to be relevant in the test task, (2) the PE stimulus is presented in one context but the test is conducted in a different context, and (3) the stimulus PE group is compared with a group that is tested with a novel stimulus in a novel context (NOV group).

In short, stimulus preexposure may produce different effects, some of which depend on the conditions of preexposure and others on those of test. Nor do such preexposures have consequences that are limited to impairment or enhancement of performance on tests of learning. For 
example, a novel item among familiar (preexposed) distractors can be localized more quickly than a novel item among novel distractors (novel pop-out [NPO] effect; see, e.g., Johnston \& Hawley, 1994). Other examples include the once popular stimulus familiarization effect (Cantor, 1969), in which simple stimulus preexposure, as compared with no such preexposure, produces slower responding in a choice response time (RT) task. Indeed, any two-phase experimental design can be construed as involving preexposure and test stages - as for example, studies of extinction - in which a paired conditioned stimulus (CS) and unconditioned stimulus (US) are "preexposed" in the first phase and, in the second, test phase, the CS is presented by itself. Among the various animallearning paradigms, blocking, overshadowing, sensory preconditioning, and many others also conform to a preexposure-and-test design.

Note that all of these paradigms employ multitrial preexposure and test stages, in which the trials that define each stage are blocked. As opposed to these designs, there are paradigms, typically used with human subjects, in which the preexposed stimuli and the test stimuli are presented in multitrial pairs, as in negative priming, Stroop tasks, flanker tasks, and cost-benefit procedures. The blocked and paired procedures have different historical roots, as well as different underlying assumptions. Curiously, there have been few attempts at a theoretical integration of the data generated from the two types of paradigms. For our purposes, it is sufficient to mention that the blocked trials procedures are commonly found in animal experiments that address theoretical issues centered on learning and that may or may not appeal to attentional explanations. On the other hand, the paired trial procedures are most commonly found in experiments with human subjects that center on problems of attention and that may or may not appeal to learning explanations.

However, as has long been recognized, attention and learning are intimately related. Indeed, any theory that posits that stimulus preexposure modulates attention will predict multiple preexposure effects, from perceptual to cognitive. A reduction of attention to a tone should affect the perceived intensity of the tone (salience) and, as a consequence, its subsequent associability. Similarly, a visual shape that has been presented as an irrelevant stimulus not only will be weakened in its ability to enter into, or reflect performance of, new associations (e.g., BraunsteinBercovitz \& Lubow, 1998a, 1998b), but also should be less effective as a target in a visual search task (Lubow \& Kaplan, 1997). Just as modulations of attention can affect learning, learning can affect attention-as for example, in various interpretations of the research on perceptual learning (Gibson, 1969), the "acquired distinctiveness of cues" (e.g., Lawrence, 1949), and LI (Lubow, 1989; Lubow, Weiner, \& Schnur, 1981).

Despite these intuitively obvious relationships, until recently there has been no study directed at showing that the LI effect is, in fact, based on a stimulus-specific loss of attention. Instead, the hypothetical decline of such attention during the preexposure period has been affirmed, albeit circularly, by the LI effect itself (for exceptions, see Braunstein-Bercovitz, Hen, \& Lubow, 2004; BraunsteinBercovitz \& Lubow, 1998a). However, this situation can be corrected, if one can demonstrate that the same set of stimulus PE conditions that produces degraded performance on a learning task (traditional LI) also leads to relatively poor performance on a task that assesses attention but is independent of the learning-based LI tests.

To this end, we have used visual search tasks that do not engage memory retrieval processes. The target is defined as a unique figure among a group of similar distractors, rather than as a function of historical experiential factors. By manipulating preexposure variables that normally produce LI and assessing performance on an attentionally modulated visual search task, one can attain a better comprehension of the processes governing LI, as well as of visual search itself. In order to understand the relationship between the visual search analogue of LI and standard learning-based LI, it is first necessary to describe a representative LI procedure of the latter type.

\section{Eliciting Standard LI in Humans}

Braunstein-Bercovitz and Lubow (1998a, 1998b) used a typical procedure for inducing LI in adult humans. The experiments were composed of two phases: preexposure and test. In Phase 1, the stimulus-preexposed subjects (PE group) were presented with 256 trials. Each trial contained the same pair of identical meaningless shapes. Concurrently, a pair of letters from the set TT, LL, TL, or LT was displayed in the space between the two shapes. The subjects were required to judge whether the letter pairs were identical (TT, LL) or different (TL, LT). This masking task served to divert attention from the shape that later, in the test phase, would be the stimulus to be learned. The nonpreexposed subjects (NPE group) received the same masking task, but without the shapes. In the test phase, the letter pairs from the masking task continued to be present in the same position as in the preexposure phase, but they were now irrelevant. On test trials, the shape that was preexposed was presented to both the PE and the NPE groups. The subjects had to learn that a change in the numerical value on a counter was associated with the presence of the shape pair that was previously irrelevant for the PE group (when the preexposed shape pair was present, a barpress decreased the number on the counter; a failure to press increased it). The PE group reached the learning criterion (five consecutive correct responses) more slowly than the NPE group did, thereby demonstrating the LI effect (for examples of recent similar findings, see Braunstein-Bercovitz, Hen, \& Lubow, 2004; N. S. Gray et al., 2001).

\section{The Basic Visual Search LI Procedure}

The visual search procedure for generating LI-like effects differs from the standard learning-based LI procedures in that it uses a within-subjects, as opposed to a between-subjects, design. In addition, the primary dependent variable is RT, rather than correct responses 
(CRs). As with the standard LI task, the LI-related visual search procedures have two stages: preexposure and test. In both stages, the subject has to detect a target that is a unique complex shape among a field of identical distractors. In some experiments, the subject is required to indicate whether the target is present or absent, and in others whether it is on the right or the left side of the display. The targets and distractors are meaningless fiveline figures (Musen \& Treisman, 1990).

The preexposure stage consists of 80-100 trials. Each trial consists of a display with the same set of common distractors. In the target present/absent experiments, some trials contain the target, and others do not. In the target right/left experiments, the target appears on every trial. In all cases, the positions of the target and the distractors vary from trial to trial. The test stage, also consisting of 80-100 trials, is initiated immediately after preexposure. For all experiments, the response requirements in the test phase are the same as those in the preexposure phase. On any given trial, the test phase target is congruent with its status during the preexposure phase (a target in both phases, $\mathrm{T} \rightarrow \mathrm{T}$ ), incongruent (a distractor during the preexposure phase becomes a target during the test, $\mathrm{D} \rightarrow \mathrm{T}$ ), or novel $(\mathrm{N})$. Similarly, on any given trial, the test phase distractors are congruent $(\mathrm{D} \rightarrow \mathrm{D})$, incongruent $(\mathrm{T} \rightarrow \mathrm{D})$, or novel $(\mathrm{N})$ in relationship to their status in the preexposure phase. The complete designation of a test phase trial, then, requires two expressions: one for the target and one for the distractor. For convenience, we will use a notational system in which the status of the test phase target is described by the first term in the expression and the status of the test phase distractor by the second term. Thus, for example, the notation $(\mathrm{D} \rightarrow \mathrm{T}):(\mathrm{T} \rightarrow \mathrm{D})$ indicates that the test phase target was previously a distractor $(\mathrm{D} \rightarrow \mathrm{T})$ and the test phase distractor was previously a target $(\mathrm{T} \rightarrow \mathrm{D})$. Given the three possible states of test phase targets and of test phase distractors, seven test phase display types can be constructed, ${ }^{1}$ although in practice we often use as few as three or four.

As an illustration of a typical procedure, in the preexposure phase, subjects are given multiple trials, each of which contains the same target and the same set of identical distractors. In the test phase, the subjects might receive four types of trials, intermixed in random order. In one type, the test trial is identical to the preexposure trials, $(\mathrm{T} \rightarrow \mathrm{T}):(\mathrm{D} \rightarrow \mathrm{D})$; in another, the test trial represents a reversal of the preexposure trial $(\mathrm{D} \rightarrow \mathrm{T}):(\mathrm{T} \rightarrow \mathrm{D})$; in another, the test trial might contain a completely novel target and novel distractors (N:N); and in a fourth trial type, there might be a partial reversal from the preexposure trial, as when the test phase target is novel but the target of the preexposure phase becomes the test phase distractor $(\mathrm{N}):(\mathrm{T} \rightarrow \mathrm{D})$.

\section{The Formal Relation Between Standard and Visual Search LI Paradigms}

The claim that the visual search paradigm described above provides an instance of independent attentional in- volvement in standard LI is based on the premise that the $(\mathrm{D} \rightarrow \mathrm{T}):(\mathrm{T} \rightarrow \mathrm{D})$ and the $(\mathrm{N}):(\mathrm{T} \rightarrow \mathrm{D})$ visual search conditions are analogous to the PE and the NPE conditions of the learning-based LI paradigm. From the previous description of a typical human learning-based LI procedure (Braunstein-Bercovitz \& Lubow, 1998a, 1998b), it should be recalled that the preexposure phase contained masking task stimuli-the TT, LL, TL, and LT letter pairs of the similarity/difference judgment task. The masking task required the subject to allocate attention to the letter pairs. Concurrently, the visual shapes, which would become the targets in the test phase, were relatively unattended. In the test, the previous masking task stimuli continued to appear on the screen. Thus, in the standard LI test phase, the PE group is confronted with a reversal of the preexposure target and distractor conditions. The target in the preexposure phase becomes a distractor in the test, and the distractor in the preexposure phase becomes a target in test, as in the visual search procedure $(\mathrm{D} \rightarrow \mathrm{T}):(\mathrm{T} \rightarrow \mathrm{D})$. On the other hand, the group that was not preexposed to the test phase target stimulus was presented with a novel target in the test phase, while at the same time receiving the same masking task stimuli in the preexposure and test phases as those of the PE group. Thus, the NPE group of standard LI is equivalent to the $(\mathrm{N}):(\mathrm{T} \rightarrow \mathrm{D})$ condition in visual search. In short, the PE and the NPE conditions of the traditional between-subjects LI experiment correspond, functionally, to the $(\mathrm{D} \rightarrow \mathrm{T})$ : $(\mathrm{T} \rightarrow \mathrm{D})$ and the $(\mathrm{N}):(\mathrm{T} \rightarrow \mathrm{D})$ within-subjects conditions of the visual search experiments. To make the notations similar to those used in the more traditional LI experiments, these two conditions, $(\mathrm{D} \rightarrow \mathrm{T}):(\mathrm{T} \rightarrow \mathrm{D})$ and $(\mathrm{N}):(\mathrm{T} \rightarrow \mathrm{D})$, will now be referred to as PE and NPE, respectively.

The asserted similarities of conditions in the two paradigms, by themselves, do not validate the claim that they elicit behaviorally similar effects or that such effects, if present, are governed by the same underlying process, attentional or otherwise. This remains to be shown empirically, which we will do in a subsequent section.

\section{The Locus of the LI Effect: PE or NPE?}

In addition to providing information regarding the role of attention in the development of LI, the visual search design permits one to assess NPO effects. NPO is defined as faster responding to a novel target in a familiar array of distractors than to a novel target with novel distractors (Johnston \& Hawley, 1994). The relationship between NPO and LI is of interest because the two paradigms share a common condition, NPE. The control or baseline condition in LI is the experimental one in the NPO paradigm. This suggests that the LI effect, poorer test performance of the PE than of the NPE group, which is attributed to a process occurring in the PE group, in fact may arise from two independent sources (Lubow, 1997). The relatively poor performance of the PE group may be a result of decreased attention to the preexposed stimulus at the time of test. On the other hand, it may be that the NPE group has relatively superior performance 
because, at the time of test, the target is a novel stimulus presented on a background of familiar distractors, a condition for attracting attention and producing NPO. In the course of reviewing the LI-like visual search effects, the role of NPO in contributing to those effects will also be assessed.

\section{Overview}

The present article provides, for the first time, a review and appraisal of the LI visual search literature and its impact on theories of LI and the processing of irrelevant information, particularly in normal participants and schizophrenic patients. As such, it complements LI reviews that have focused on standard preparations (animal and human; e.g., Lubow, 1989), psychopharmacology (e.g., Weiner, 2003), schizotypality (Braunstein-Bercovitz et al., 2002), and schizophrenia (Escobar et al., 2002; Lubow, 2005; Lubow \& Gewirtz, 1995). More specifically, the review makes the case for the involvement of selective attentional processes in LI in the devaluation of irrelevant stimuli and in the disruption of those processes in schizophrenia. In addition, the visual search LI data are used to reconcile two opposing views of LI, attentional and retrieval/competition.

Given the differences between traditional learningbased LI procedures that use between-subjects designs, with $\mathrm{CR}$ as the dependent variable, and the newer visual search procedures that use within-subjects designs, with RT as the dependent variable, as well as the gross dissimilarities of general procedures, it is first necessary to defend the contention that learning-based LI and visualsearch-based LI are related phenomena-namely, that they are governed by the same attention-related processes. If traditional LI is modulated by attentional processes, as has been proposed by some (e.g., Lubow et al., 1981; Mackintosh, 1975; Pearce \& Hall, 1980) but discounted by others (e.g., Bouton, 1993; Bouton, Nelson, \& Rosas, 1999; Escobar et al., 2002; Miller, Kasprow, \& Schachtman, 1986), then in the attentionally controlled visual search task, RT in the PE condition should be longer than that in the NPE condition. The next section will provide such data from a series of experiments with three related visual search procedures in which unique targets and common distractors were used.

Following this, evidence will be presented that the individual difference variables that modulate traditional LI - specifically, age, gender, and level of schizotypalityhave comparable effects on performance in the visual search analogue of LI. Similarly, it will be shown that clinically diagnosed groups, including patients with schizophrenia and Parkinson's disease (PD) and children with anxiety disorders, provide the same pattern of data on traditional and visual search LI. The penultimate section will address a number of theoretical issues, including attentional and retrieval accounts of LI. The last section will offer a description of the attentional processes that underlies the stimulus preexposure effects that are reflected in learning-based and visual-search-based LI.

\section{THE LI- RELATED VISUAL SEARCH PROCEDURES}

Three sets of visual search procedures, all of which have a number of common features, are related to standard LI. As has already been noted, the preexposure and test phases are composed, with one exception (Lubow \& Kaplan, 1997, Experiment 1), of identical visual search tasks. Although the similarities across experiments are fundamental to their purpose of providing a visual search analogue for LI, there are also a number of differences among them, primarily in regard to number of target trial types in the test phase and the kind of response required for target detection. When trials without a target are interspersed with trials that contain a target, target detection is indexed by a response of presence or absence. When targets are present on all trials, the subject is required to respond to whether the target is on the right or the left side of the screen. Experiments in which the different procedures have been used will be reviewed below. In addition to the response requirements, the experiments differ in terms of the number of within-subjects conditions in the test phase.

\section{Seven Target/Distractor Test Conditions, Target Present or Absent}

The first visual search LI analogue experiments presented subjects with all of the seven possible test phase conditions, with targets either present or absent. Table 1 (top) shows the mean RTs, for normal groups, for the three visual search conditions (PE, NPE, and NOV) from which LI and NPO effects are generated (Lubow, Dressler, \& Kaplan, 1999; Lubow \& Kaplan, 1997, Experiment 2; Lubow, Kaplan, Abramovich, Rudnick, \& Laor, 2000; Lubow, Toren, Laor, \& Kaplan, 2000). LI magnitude was computed by the formula (PE-NPE)/NPE, and NPO by (NOV-NPE)/NPE, in which the PE, NPE, and NOV values are mean RTs for those conditions. LI and NPO effects are indexed by positive ratios, where the higher the ratio is, the greater the effect will be. A negative ratio indicates a reversal of the effect.

From Table 1, it can be seen that the subjects in all four studies responded more slowly in the PE than in the NPE condition, thereby demonstrating the basic LI analogue effect. In addition, RTs in the PE condition were quite similar to those in the NOV condition. The difference in RTs between each of these and the NPE condition defines LI and NPO, respectively. Since the LI and NPO effects are both present, the data are ambiguous in regard to the source of the LI effect. In other words, the LI effect, the difference between PE and NPE, may derive from faster target-distractor processing in the NPE condition than in the PE condition or, as the accepted view of LI would have it, as a consequence of a difference in processing in the PE, as compared with the NPE, condition. However, as will be seen in a later section, LI also can be obtained in the absence of any NPO effect (e.g., Kaplan \& Lubow, 2001). 
Table 1

Mean Target Detection Response Times (RTs, in Seconds) for Three Visual Search ConditionsPreexposed (PE), Nonpreexposed (NPE), and Novel (NOV) — and Magnitudes of Latent Inhibition (LI) and Novel Pop-Out (NPO) Effects for Normal Groups in Experiments with Target/No-Target Test With Seven Test Conditions and in Left-Right Procedure With Three Display Conditions

\begin{tabular}{|c|c|c|c|c|c|}
\hline \multirow[b]{2}{*}{ Source } & \multicolumn{3}{|c|}{ RT } & \multirow[b]{2}{*}{ LI } & \multirow[b]{2}{*}{ NPO } \\
\hline & $\mathrm{PE}$ & NPE & NOV & & \\
\hline \multicolumn{6}{|c|}{ Seven Conditions: Target/No Target } \\
\hline Lubow \& Kaplan (1997, Experiment 2) & 1.34 & 1.20 & 1.37 & .12 & .14 \\
\hline Lubow, Dressler, \& Kaplan (1999) & 2.55 & 1.90 & 2.35 & .34 & .24 \\
\hline Lubow, Kaplan, Abramovich, Rudnick, \& Laor (2000) & 2.10 & 1.90 & 2.03 & .11 & .07 \\
\hline Lubow, Toren, Laor, \& Kaplan $(2000)^{*}$ & 1.95 & 1.65 & 1.95 & .18 & .18 \\
\hline \multicolumn{6}{|c|}{ Three Conditions: Target, Left/Right } \\
\hline \multicolumn{6}{|l|}{ Lubow, Kaplan, \& De la Casa (2001) } \\
\hline Experiment 1 & 1.90 & 1.58 & 1.68 & .20 & .06 \\
\hline Experiment 2 & 1.76 & 1.56 & 1.57 & .13 & .01 \\
\hline
\end{tabular}

As has been noted, the four experiments shared the following characteristics: (1) Phases 1 and 2 consisted of identical visual search tasks, and (2) Phase 2 was composed of seven different target-distractor trial types (although only a subset of these will be reported). These properties raise two questions. First, the rationale for the experiments was based on the supposition that Phase 1 produces an attended target and an unattended distractor, as in the preexposure phases of standard LI experiments. Lubow and Kaplan (1997, Experiment 1) examined this assumption with a procedure developed by Rock and Gutman (1981). In Phase 1, instead of a visual search task, subjects viewed a figure-ground display consisting of two overlapping visual patterns of different colors. On each presentation, the subjects were required to rate, for example, a red figure on a scale of aesthetic preference. Thus, the red figure was attended, whereas a green figure, which lay behind the red one, was irrelevant and unattended. Rock and Gutman found that subjects could recall the shapes of the attended, but not the unattended, figures.

We used this procedure for the preexposure phase but followed it with a visual search task in which the previously attended and the unattended stimuli took on the roles of targets or distractors, as has previously been described. The results were similar to those in Lubow and Kaplan (1997, Experiment 2), where the Phase 2 visual search task was preceded by another visual search task. The fact that LI and NPO effects in the visual search task were generated with both preexposure procedures, one of which is generally accepted as producing unattended stimuli (Rock \& Gutman, 1981), supports the position that the distractor stimuli in the subsequent experiments, in which visual search was used as the instrument of preexposure, were, indeed, unattended.

\section{Three Target Trial Test Conditions, Target Present or Absent}

By reducing the number of trial types in the test phase, the detection task is made easier, and the possibility of in- terference from conditions that are not theoretically relevant is reduced. Table 2 presents the results of those studies, together with data related to block and context effects.

In general, Table 2 indicates that LI-like effects are evident even with a reduction of the number of trial types. In addition, generating the LI effect requires that the test stage contain some trials that are identical to that in the preexposure stage (reminder trials) and that the context is the same in preexposure and test. These results are

Table 2

Mean Target Detection Response Times (RTs, in Seconds) for Three Visual Search Conditions-Preexposed (PE), Nonpreexposed (NPE), and Novel (NOV)—and Latent Inhibition (LI) and Novel Pop-Out (NPO) Magnitudes for Normal Subjects

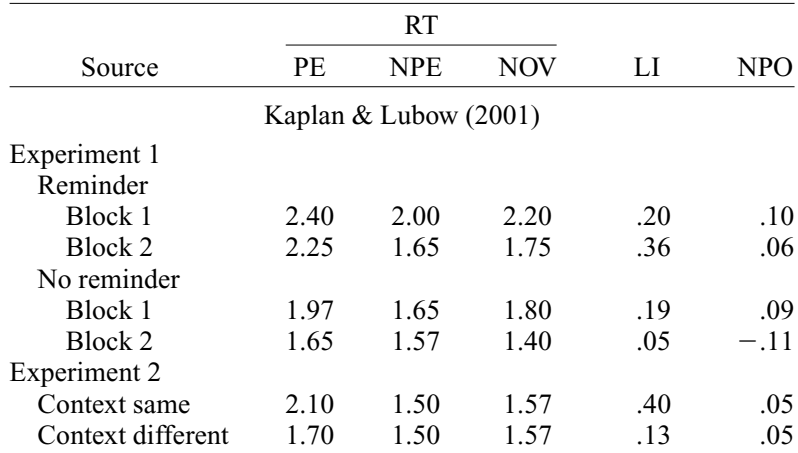

Gibbons, Rammsayer, \& Lubow (2001)*

Experiment 1

\begin{tabular}{llllll} 
Block 1 & 1.55 & 1.50 & - & $.03^{\dagger}$ & - \\
Block 2 & 1.34 & 1.37 & - & -.02 & - \\
Block 3 & 1.30 & 1.37 & - & $-.05^{\dagger}$ & - \\
Experiment 2 & & & & & \\
Block 1 & 1.44 & 1.34 & - & $.07^{\dagger}$ & - \\
Block 2 & 1.20 & 1.20 & - & .00 & - \\
Block 3 & 1.12 & 1.13 & - & -.01 & - \\
\hline
\end{tabular}

Note-LI $=(\mathrm{PE}-\mathrm{NPE}) / \mathrm{NPE} ; \mathrm{NPO}=(\mathrm{NOV}-\mathrm{NPE}) / \mathrm{NPE}$ (from experiments with target/no-target test and three target trial conditions). *Data estimated from figures. †PE vs. NPE, $p<.05$. †Definitions of PE and NPE are different from those in other studies; $\mathrm{PE}=\mathrm{D} \rightarrow \mathrm{T}: \mathrm{N}$; $\mathrm{NPE}=\mathrm{N}: \mathrm{N}$. 
congruent with those from the experiments with seven trial types, all of which contained reminder trials and had the same context in the preexposure and the test phases.

\section{Three Target Trial Test Conditions, Target Present on All Trials}

More recently, we have simplified the visual search task even further (Lubow, Kaplan, \& De la Casa, 2001). Unlike the previously described procedures that required subjects to identify the presence or absence of a unique target, the new procedure displays the target on every trial, and the subject must indicate whether the target is on the left or the right side of the screen. Table 1 (bottom) displays the mean RTs for PE, NPE, and NOV conditions for Lubow et al.'s (2001) study. As can be seen, the left/right procedure also was effective in producing LI-like effects. Particularly noteworthy is the fact that variance of mean RTs in the left/right procedure is considerably smaller than that in the target/no-target procedure. However, as can be seen in Table 1, the NPO effect was severely compromised. In opposition to the four studies in which the seven-condition test procedure was used, all of which reported significant NPO effects, Experiment 1 with the new procedure provided only a marginally significant NPO effect $(p=.08)$, and Experiment 2 none at all.

The difference in results between the two sets of studies suggests that the higher ratio of NOV and NPE trials to PE trials in the three-condition, as opposed to the seven-condition, procedure, together with the fact that a target appears on every trial, mitigated the influence of the preexposure phase. Indeed, one might expect that in the all-target, three-condition procedure, the novelty of the target and the distractor in the NOV condition would dissipate more rapidly than in the seven-condition procedure, in which there are both target and no-target trials. This hypothesis receives some support from a reanalysis of the data from Lubow et al., 2001 (Experiment 1). The NPO effect was obtained in the all-target, three-condition procedure, but only in the early blocks. When the test trials were divided into two blocks, the difference in RT between the NPE and the NOV conditions (NPO) was significant in the first block $(23 \mathrm{msec})$, but not in the second block (1 msec). A similar comparison of PE and NPE conditions indicated that the LI effect was significant in both the first and the second blocks ( 35 and $30 \mathrm{msec}$, respectively). In Experiment 2, the pattern of results was less clear. NPO effects were small in Blocks 1 and 2 (4 and $3 \mathrm{msec}$, respectively).

That the LI-like effect survives the demise of NPO undermines the suggestion that LI may be due to two different processes (Lubow, 1997), one residing in the PE condition/group and related to the stimulus-specific decline in attention, and one in the NPE condition/group, which represents an NPO effect-namely, the capture of attention by a novel stimulus among a field of familiar stimuli (Johnston \& Hawley, 1994).

\section{INDIVIDUAL DIFFERENCE VARIABLES}

In this section, we will review the visual search LI data related to individual difference variables such as age and gender, as well as to differences, among normal subjects, in self-administered questionnaire test scores for schizotypality and anxiety. In addition, we will examine visual search LI data from clinically diagnosed pathological groups, including schizophrenic and PD patients and anxiety disorder and ADHD children. In each case, the visual search data will be related to that from matched normal controls and to comparable data from standard LI.

\section{Age}

Although age, as such, was not a variable in any of the experiments, there are enough differences in the ages of groups across experiments to allow for some tentative conclusions. Table 3 presents the visual search data from normal groups, whose ages varied from 12 to 59 years. As can be seen, there is no evidence of an age-related pattern.

As opposed to the absence of an age effect, Lubow (1989) concluded, mostly from the conditioned taste aversion studies with animals, that LI is present in young weanling, as well as in mature, rats but that it is weakened or abolished in senescent animals. With learningbased LI in humans, the situation is more complex, since a masking task is usually required to elicit LI in older children and adults, but not in children below the age of

Table 3

Mean Target Detection Response Times (RTs, in Seconds) of Normal Subjects for Three Visual Search Conditions-Preexposed (PE), Nonpreexposed (NPE), and Novel (NOV)—and Latent Inhibition (LI) and Novel Pop-Out (NPO) Effect Magnitudes as a Function of Age (in Years)

\begin{tabular}{|c|c|c|c|c|c|c|c|}
\hline \multirow[b]{2}{*}{ Source } & \multirow[b]{2}{*}{ Mean Age } & \multirow[b]{2}{*}{ Range } & \multicolumn{3}{|c|}{ RT } & \multirow[b]{2}{*}{ LI } & \multirow[b]{2}{*}{ NPO } \\
\hline & & & $\mathrm{PE}$ & NPE & NOV & & \\
\hline Lubow, Toren, Laor, \& Kaplan (2000) & 12.0 & $6-17$ & 1.95 & 1.65 & 1.95 & .18 & .18 \\
\hline E. Cohen et al. (2004) & 16.0 & $14-18$ & 1.51 & 1.34 & 1.47 & .13 & .10 \\
\hline Lubow, Kaplan, \& De la Casa (2001, Experiment 2) & 18.5 & $17-28$ & 1.76 & 1.56 & 1.57 & .13 & .01 \\
\hline Lubow \& Kaplan (1997, Experiment 2) & 22.5 & $18-30$ & 1.34 & 1.20 & 1.37 & .12 & .14 \\
\hline Kaplan \& Lubow (2001, Experiment 2) & 22.5 & $20-28$ & 2.10 & 1.50 & 1.57 & .40 & .05 \\
\hline Lubow et al. (2001, Experiment 1) & 22.8 & $20-30$ & 1.90 & 1.58 & 1.68 & .20 & .06 \\
\hline Lubow, Kaplan, Abramovich, Rudnick, \& Laor (2000) & 34.1 & $22-58$ & 2.10 & 1.90 & 2.03 & .11 & .07 \\
\hline Lubow, Dressler, \& Kaplan (1999) & 58.7 & $37-77$ & 2.55 & 1.90 & 2.35 & .34 & .24 \\
\hline
\end{tabular}

Note- $-\mathrm{LI}=(\mathrm{PE}-\mathrm{NPE}) / \mathrm{NPE} ; \mathrm{NPO}=(\mathrm{NOV}-\mathrm{NPE}) / \mathrm{NPE}$. 
6 years (e.g., Lubow \& Josman, 1993). Using an auditory LI task with masked preexposure, Swerdlow, Magulac, Filion, and Zinner (1996) compared older children (mean age of 11.5 years) and adults (mean age of 32.8 years). They found no differences in LI magnitude. Thornton et al. (1996) also concluded that for adults, LI was age independent.

Thus, the human LI literature is fairly consistent. Both standard and visual search LI procedures do not produce an effect of age, at least within the range of 12-59 years. In animal preparations, LI appears to decrease with age. The difference between the two sets of data may well be due to the restricted range of ages in the human studies.

\section{Gender}

Table 4 presents LI and NPO effects for the several visual search LI experiments that had male and female subgroups. As can be seen, there is a trend for more LI in males than in females. If true, this would be congruent with the data from standard human LI preparations (Golosheiken, Volf, \& Razumnikova, 1997) and from a reanalysis of a large set of LI data from the Queensland and Giessen laboratories. In the latter, $60.6 \%$ of the male subjects, but only $37.2 \%$ of the female subjects, exhibited LI (Lipp, personal communication). Lower LI in women than in men may be due to higher experiment-induced anxiety levels in the former (Braunstein-Bercovitz, 2000). However, some experiments have not shown a gender effect for LI (Della Casa, Höfer, \& Feldon, 1999; Swerdlow, Braff, Hartston, Perry, \& Geyer, 1996; Swerdlow, Hartston, \& Hartman, 1999; Swerdlow, Magulac, et al., 1996). ${ }^{2}$

The lack of clarity as to male-female differences in LI may be related to the findings that LI magnitude is a function of an interaction between gender and other individual difference variables. Thus, with de novo PD patients, female patients with right-side motor symptoms (left-hemisphere dopamine depletion) had elevated LI effects, as compared with female controls and with female PD patients with left-side motor impairment (Lubow et al., 1999). On the other hand, studies with schizo- phrenic patients (Lubow, Kaplan, et al., 2000) and low and high schizotypals (Lubow et al., 2001, Experiment 2) indicate that LI magnitude is larger in normal females than in female schizophrenic patients (but see E. Cohen et al., 2004) and in low-schizotypal than in high-schizotypal females (Lubow et al., 2001, Experiment 2). Comparable male groups did not exhibit this pattern. A recent standard LI study (Lubow \& De la Casa, 2002), in which a within-subjects design with RT as the dependent measure was used, also showed significant LI effects in low-schizotypal, but not high-schizotypal, females. In males, the pattern was reversed.

Relatedly, there is evidence of increased striatal dopamine in women, as compared with men (Pohjalainen, Rinne, Nagren, Syvalahti, \& Hietala, 1998). Dopamine is associated with the positive symptoms of schizophrenia, and dopamine agonists, such as amphetamine, attenuate LI and produce mild positive symptoms in normal subjects (e.g., N.S. Gray, Pickering, Hemsley, Dawling, \& Gray, 1992). The inverse relation between LI and positive symptoms, coupled with the fact that women tend to have more positive symptoms than do men, is congruent with the assumption of weaker LI in women than in men. These findings also are compatible with the LI schizotypy literature, in that females tend to score higher than males on schizotypy subscales that tap positive symptoms (Raine, 1992; see also J. A. Gray, Feldon, Rawlins, Hemsley, \& Smith, 1991; N. S. Gray, Hemsley, \& Gray, 1992), and high schizotypy is associated with reduced LI (see below).

In brief, women, both schizophrenic patients and highschizotypal normals, tend to have more positive symptoms than do men, whereas men tend to have more negative symptoms than do women (Raine, 1992). This pattern fits with the suggestion that males should have more LI than females do. ${ }^{3}$

Although the animal literature does not provide evidence for basic LI differences between male and female rats, LI in male rats, as compared with female rats, is more vulnerable to loss by a variety of stress-related manipulations (e.g., Peters, Gray, \& Joseph, 1991; Shalev,

Table 4

Mean Target Detection Response Times (RTs, in Seconds) of Normal Subjects for Three Visual Search Conditions - Preexposed (PE), Nonpreexposed (NPE), and Novel (NOV)—and Latent Inhibition (LI) and Novel Pop-Out (NPO) Effect Magnitudes as a Function of Gender

\begin{tabular}{|c|c|c|c|c|c|c|}
\hline \multirow[b]{2}{*}{ Source } & \multirow[b]{2}{*}{ Gender } & \multicolumn{3}{|c|}{ RT } & \multirow[b]{2}{*}{ LI } & \multirow[b]{2}{*}{ NPO } \\
\hline & & PE & NPE & NOV & & \\
\hline \multicolumn{7}{|l|}{ Lubow, Kaplan, \& De la Casa (2001) } \\
\hline \multirow[t]{2}{*}{ Experiment 1} & Male & 2.00 & 1.60 & 1.65 & .25 & .03 \\
\hline & Female & 1.80 & 1.55 & 1.70 & .16 & .10 \\
\hline \multirow[t]{2}{*}{ Experiment 2} & Male & 1.57 & 1.31 & 1.36 & .20 & .04 \\
\hline & Female & 1.75 & 1.60 & 1.61 & .09 & .01 \\
\hline \multirow[t]{2}{*}{ Lubow, Dressler, \& Kaplan (1999) } & Male & 2.93 & 2.12 & 2.44 & .38 & .15 \\
\hline & Female & 2.48 & 1.95 & 2.41 & .27 & .24 \\
\hline \multirow[t]{2}{*}{ Lubow, Kaplan, Abramovich, Rudnick, \& Laor (2000) } & Male & 1.86 & 1.82 & 2.04 & .02 & .12 \\
\hline & Female & 2.33 & 1.98 & 2.02 & .18 & .02 \\
\hline
\end{tabular}

Note-LI $=(\mathrm{PE}-\mathrm{NPE}) / \mathrm{NPE} ; \mathrm{NPO}=(\mathrm{NOV}-\mathrm{NPE}) / \mathrm{NPE}$. 
Feldon, \& Weiner, 1998; Shalev \& Weiner, 2001; Weiner, Feldon, \& Ziv-Harris, 1987; Weiner, Schnabel, Lubow, \& Feldon, 1985).

\section{Schizophrenia and Schizotypality}

LI is widely accepted as an index of the ability to ignore irrelevant stimuli. As such, it has been used as a tool to evaluate attentional dysfunction in schizophrenic patients (for reviews, see J. A. Gray, 1998; Lubow \& Gewirtz, 1995). The rationale for this approach is based on dopamine-animal models of schizophrenia, particularly the fact that LI is mediated by mesolimbic dopaminergic activity (for reviews, see J. A. Gray, 1998; Moser, Hitchcock, Lister, \& Moran, 2000; Weiner \& Feldon, 1997), most likely impulse-dependent events in the nucleus accumbens that occur at the conditioning stage (Joseph et al., 2000; for a review, see Joseph, Datla, \& Young, 2003).

The model is supported by the following additional empirical findings. (1) LI is attenuated by schizophreniarelated indirect dopamine receptor agonists, such as $d$ amphetamine, both in animals (e.g., Weiner, Lubow, \& Feldon, 1984; for reviews, see Moser et al., 2000; Weiner \& Feldon, 1997) and in healthy humans (N. S. Gray, Pickering, et al., 1992; Kumari et al., 1999; Swerdlow et al., 2003; Thornton et al., 1996). (2) LI is potentiated by nonselective dopamine receptor antagonists, such as haloperidol, which is an effective neuroleptic - again, both in animals (e.g., Weiner, Feldon, \& Katz, 1987; for reviews, see Moser et al., 2000; Weiner \& Feldon, 1997) and in healthy humans (Kumari et al., 1999; Williams et al., 1996; Williams et al., 1997). ${ }^{4}$ (3) As required by the model, LI is reduced or abolished in recently medicated, acute schizophrenic patients (Baruch, Hemsley, \& Gray, 1988a; N. S. Gray, Hemsley, \& J. A. Gray, 1992; N. S. Gray, Pilowsky, J. A. Gray, \& Kerwin, 1995; Rascle et al., 2001; Sitskoorn, Salden, \& Kahn 2001; but see Swerdlow, Braff, et al., 1996, and Williams et al., 1998). As opposed to this, chronic and medicated schizophrenic patients exhibit normal LI. Although most studies have reported no difference in LI between the latter two groups (e.g., Baruch et al., 1988a; Leumann, Feldon, Vollenweider, \& Ludewig, 2002; Martins Serra, Jones, Toone, \& Gray, 2001), Rascle et al. (2001) have described a super-LI effect in chronic schizophrenic patients, as compared with normals. ${ }^{5}$ (4) Finally, LI is attenuated in high-schizotypal, as compared with low schizotypal, normals (for reviews, see Braunstein-Bercovitz et al., 2002; Lubow \& Gewirtz, 1995; also see below). The latter is consistent with a continuity model of psychopathology, which proposes that psychotic tendencies exist on a continuum, at one pole of which is a normal population and at the other a hospitalized patient group (e.g., Claridge, 1985; Eysenck \& Eysenck, 1976; Zubin \& Spring, 1977). In support of the continuity model, Vollema and van den Bosch's (1995) review of nine factor-analytic studies points to the striking similarities between schizotypal traits and schizophrenic symptoms (see also Gruzelier, 1996; Gruzelier \& Doig, 1996).
As has been noted, low- and high-schizotypal normals, identified on the basis of scores on self-report questionnaires, such as the Schizotypal Personality Questionnaire (SPQ; Raine, 1991) and the Schizotypal Trait Questionnaire (Claridge \& Broks, 1984), display significantly different levels of LI. Specifically, high schizotypals exhibit reduced standard LI, as compared with low schizotypals (e.g., Baruch, Hemsley, \& Gray, 1988b; BraunsteinBercovitz, 2000; Braunstein-Bercovitz \& Lubow, 1998a; N S. Gray, Fernandez, Williams, Ruddle, \& Snowden, 2002; Lipp, Siddle, \& Arnold, 1994; Lipp \& Vaitl, 1992; but see Wuthrich \& Bates, 2001, who found that LI was an inverted U-shaped function of schizotypy level). Relatedly, a recent study has reported the absence of a significant LI effect in both high and low schizotypals who were firstdegree relatives of chronic schizophrenic patients, who themselves did not show LI (Martins Serra et al., 2001).

The reduced LI in schizophrenic patients and in highschizotypal normals has been interpreted as reflecting dysfunctional attentional processing. More specifically, since normal LI is assumed to be the result of a stimulusspecific decline in attention with repeated presentations of an irrelevant stimulus, attenuated LI has been attributed to a failure to reduce the attentional response to the irrelevant stimulus (Lubow \& Gewirtz, 1995). This hypothesis fits well with the many reports that the attentional dysfunction in schizophrenia is characterized by high distractibility and by a difficulty in switching from controlled to automatic processing of irrelevant stimuli (e.g., J. A. Gray et al., 1991; Hemsley, 1987; Nuechterlein \& Dawson, 1984).

The attentional dysfunction explanation of LI deficits in schizophrenic patients and high-schizotypal normals in standard LI preparations is supported by the visual search LI data. In an unpublished study, Lubow et al. (2002) administered the SPQ to a large sample of undergraduate women, who were then divided into low-, mid-, and highschizotypal groups. As was expected, the high-schizotypal group exhibited less LI than the low-schizotypal group did. Lubow et al. (2001) also found reduced visual search LI in high-schizotypal, as compared with low-schizotypal, females, although a similar pattern was not present for males. More recently, Tsakanikos, Sverdrup-Thygenson, and Reed (2003), using a different visual search procedure from that of Lubow and colleagues, and with approximately equal numbers of males and females, reported reduced LI in high-schizotypal, as compared with low-schizotypal, normal groups (the effect of gender was not examined).

Lubow, Kaplan, et al. (2000) also compared a mixed group of adult schizophrenic outpatients with matched normal controls. As was predicted, normal controls, but not schizophrenics, showed the LI-like effect. However, as with schizotypal subjects (Lubow et al., 2001), the latter finding was due exclusively to the absence of normal LI in female patients.

A more recent study by E. Cohen et al. (2004) suggests that the relationship between visual search LI and 
schizophrenia may be more complex than was originally anticipated. Although healthy controls exhibited the usual LI effect, LI was potentiated in schizophrenics who simultaneously exhibited high levels of negative symptoms and low levels of positive symptoms, a pattern that may be related to length of hospitalization and/or chronicity (see also Rascle et al., 2001). Schizophrenic groups with other combinations of positive and negative symptoms did not differ from controls, a pattern suggesting that past inconsistencies in the LI schizophrenia literature may be the result of opposing processes that are associated with positive and negative symptoms.

\section{Parkinson's Disease Patients}

Of particular interest for a dopamine model of schizophrenia is an apparent reciprocal relationship between schizophrenia and PD. PD, like schizophrenia, involves dopamine dysfunction. However, schizophrenia is associated with excessive dopamine activity or dopamine receptor sensitivity, perhaps in the nucleus accumbens (J. A. Gray, 1995; J. A. Gray et al., 1991), and PD is attributed to a loss of dopamine due to substantia nigra degeneration within the basal ganglia (Agid, 1991; Gibb, 1991; Roth \& Elsworth, 1995). Despite the fact that different dopamine pathways are involved in the two diseases, mesolimbocortical and mesostriatal, there remains a general complementarity that may be related to surplus versus deficit dopamine states. Thus, treatment of schizophrenia with dopamine antagonists such as haloperidol may produce Parkinson's-like motor dysfunctions (tardive dyskinesia; Kane, 1995; Peacock, Solgaard, Lublin, \& Gerlach, 1996), whereas treatment of PD with 1-dopa may promote schizophrenia-like delusions and hallucinations (Marsden, 1994; Musser \& Akil, 1996).

If the reciprocity hypothesis is valid, cognitive processing deficits in PD should, in general, show a pattern opposite to that found in schizophrenia. Since LI is attenuated in acute nonmedicated schizophrenics, as compared with normals, and, in healthy groups, dopamine agonists attenuate LI and dopamine antagonists produce a super-LI effect, de novo PD patients (nonmedicated), because of decreased dopaminergic activity, would be expected to show super-LI when compared with normal controls. Salzman, Hadar, Korczyn, and Lubow (1994) failed to find such an effect with a typical LI procedure, perhaps because of a ceiling on LI as a result of the fact that a large number of subjects from both groups failed to reach the learning criterion. However, Schugens, Topka, and Daum (1999, p. 199), using conditioned eyeblink, did report a larger than normal LI effect in PD patients.

To overcome the ceiling effects that are inherent in the traditional LI paradigm, we administered the visual search LI task to PD patients (Lubow et al., 1999). We predicted a greater LI-like effect in the PD group than in the control group. In addition, we were able to take advantage of the fact that the onset of PD typically is lateralized, with a predominance of overt motor symptoms on either the right or the left side. The lateralization is accounted for by an asymmetric degeneration of dopaminergic nigrostriatal pathways. If LI is dopamine related, there might be some differences in LI due to differences in hemispheric dopamine activity. Indeed, there is some evidence that LI is mediated by the right hemisphere. Thus, when unattended preexposed auditory stimuli are presented to the left ear (right hemisphere), there is a significant LI effect, which is absent when the same stimuli are presented to the right ear (N. S. Gray, Pickering, et al., 1992). A similar pattern of LI has been reported for irrelevant visual stimuli presented to the right or the left visual field (Golosheiken et al., 1997). Consequently, one would expect that PD patients with primarily rightor left-hemisphere dopamine losses would exhibit different patterns of LI. Specifically, if, as the literature indicates, LI is attenuated by dopamine agonists and potentiated by dopamine antagonists and LI is mediated by the right hemisphere, PD patients with left-side motor symptoms (right-hemisphere dopamine depletion) should show the greatest enhancement of LI. On the other hand, if right-hemisphere integrity is essential for generating LI, PD patients with right-side motor symptoms (lefthemisphere dopamine depletion) should exhibit enhanced LI. Irrespective of the direction of the prediction, there should be differences in LI that are associated with side of damage. Indeed, female PD patients with right-side motor symptoms had elevated LI, as compared with female controls and female PD patients with left-side symptoms. On the other hand, male PD patients with right-side symptoms did not exhibit any LI (Lubow et al., 1999).

\section{Anxiety Disorder Children}

Although clinically diagnosed anxiety disorder children, in general, responded more slowly than normal children on the visual search task, there were differences neither in LI nor in NPO between the two groups (Lubow, Toren, et al., 2000). However, when the clinical diagnostic classification was disregarded, and the subjects were reclassified into low and high anxious on the basis of scores from the Revised Children's Manifest Anxiety Scale (RCMAS; Reynolds \& Richmond, 1985), high-anxious children had less LI than low-anxious children did, although not significantly $(p=.12)$. If proven to be reliable, the finding that a high anxiety level attenuates LI would be congruent with data from standard LI tests with ADHD children (Lubow \& Josman, 1993), as well as with attenuated LI in normal adults who score high, as opposed to low, on the Spielberger, Gorsuch, and Lushene (1970) State Anxiety Questionnaire (Braunstein-Bercovitz, 2000). Relatedly, LI in adult humans is attenuated by stress (Braunstein-Bercovitz, Dimentman-Ashkenazi, \& Lubow, 2001).

These studies, together with those that have shown that animal LI is reduced by stress (e.g., Hellman, Crider, \& Solomon, 1983; Lehmann, Stöhr, \& Feldon, 2000; Shalev et al., 1998) and by anxiogenic drugs (e.g., Feldon \& Weiner, 1989; Lacroix, Spinelli, Broersen, \& Feldon, 2000 ), indicate that LI may be impaired in any state that is 
characterized by a high stress/anxiety level (BraunsteinBercovitz et al., 2002). If true, this would undermine the suggestion that an LI deficit may be a specific marker for schizophrenia.

\section{EVIDENCE FOR IDENTITY OF PROCESS IN VISUAL SEARCH AND STANDARD LI}

As was stated in the introduction, the visual search LI experiments were initiated as a test of LI theories that implicate attentional processes. As such, the approach was based on the assumption that, irrespective of the nature of the underlying process in LI visual search, it is the same as that governing standard LI. Some evidence to support the similarity of process was presented in the section on individual differences. In the present section, we will continue to gather support for similarity of process, but now from the findings of similar effects of reminder and context variables on the two types of LI and from data describing a positive correlation between performance on the visual search and standard LI tasks.

\section{Reminder Trials}

In the case of LI, a reminder trial is defined as a preexposure stage event that is reproduced in the test stage. In general, it appears that LI is enhanced by any manipulation that increases the similarity of the prexposure and the test stages (see the next section on context effects). Thus, in the visual search analogue of LI, a test stage display that is identical to the target/distractor display of the preexposure phase $(T \rightarrow T):(D \rightarrow D)$ serves as a reminder trial. As such, most of our visual search experiments contained reminder trials. To determine whether the presence of these reminder trials does indeed enhance LI in visual search, Kaplan and Lubow (2001, Experiment 1) used groups with and without such trials. As can be seen in Table 2, the group with reminder trials showed a stronger LI effect than did the group without reminder trials, at least in the last trial block. However, significant visual search LI has also been obtained without any reminder trials (Gibbons, Rammsayer, \& Lubow, 2001).

In standard paradigms, the LI-promoting effects of context stability from preexposure to test phases (e.g., Westbrook, Jones, Bailey, \& Harris, 2000; Zalstein-Orda \& Lubow, 1995), as well as the introduction of the test phase unconditioned stimulus into the preexposure phase (Killcross \& Dickinson, 1996), have been interpreted in terms of reminder effects. Relatedly, preexposures of the to-be$\mathrm{CS}$ and the to-be-US (but not paired) produce greater decrements in subsequent learning than does preexposing either one separately (Bennett, Maldonado, \& Mackintosh, 1995; Bonardi \& Hall, 1996; Matzel, Schachtman, \& Miller, 1988). The addition of the to-be-US to the preexposure phase serves the same role as adding reminder trials to the test phase or increasing the similarity of the preexposure and the test stage contexts. On the other hand, reminder treatments aimed at retrieving the second-stage CS-US association are effective in disrupting LI (Kasprow, Catterson, Schachtman, \& Miller, 1984).
In general, it is assumed that the various reminders of preexposure stage conditions provide cues for the retrieval of the CS-0 association. As such, LI would be potentiated in a two-stage procedure as a result of the relatively strong $\mathrm{CS}-0$ association (stimulus-specific inattention) interfering with the acquisition of the new CS-US association. In a three-stage procedure, there may be two sources of LI enhancement: the LI already present from Stage 2 and an additional increase due to retrieval competition between the CS- 0 and the CS-US associations.

\section{Context Effects}

Although the particular type of reminder trial effect reported by Kaplan and Lubow (2001, Experiment 1) has no direct parallel in the LI literature, the same cannot be said for context change. Numerous studies have demonstrated that a change of context from preexposure to test phase markedly disrupts LI, both in animals (e.g., Bouton \& Brooks, 1993; McLaren, Bennett, Plaisted, Aitken, \& Mackintosh, 1994) and in humans (De la Casa \& Lubow, 2001; Escobar, Arcediano, \& Miller, 2003; N. S. Gray et al., 2001; Zalstein-Orda \& Lubow, 1995).

If the longer RTs in the PE than in the NPE condition obtained in the visual search procedure reflect an LI effect, a change of context from the preexposure to the test phase should abolish or reduce the RT difference between the PE and the NPE conditions. Indeed, Kaplan and Lubow (2001, Experiment 2) found that when the color of the background on which the visual search task was performed was the same in the preexposure and the test phases, the expected LI-like effect was obtained. However, when the context color was changed from the preexposure to the test phase, the LI-like effect was significantly attenuated (see Table 2 ).

\section{A Direct Comparison Between Visual Search and Standard LI}

The case for similarity of process in standard and visual search LI was further strengthened by Gibbons et al. (2001), who directly compared performance of the same subjects on the two tasks. If performance on the two tasks is governed by a common process, one would expect a significant positive correlation between RTs from a visual search LI index (PE minus NPE) and performance of the PE group in a standard LI learning task. Such a correlation (not reported in the original article) was obtained for the PE group (+.47; RT from Block 1 of visual search and number of CRs in the traditional rulelearning LI task). For the subjects in the NPE condition/ group, the correlation was not significant and negative, -.20 .

\section{AN INTEGRATED THEORY OF LATENT INHIBITION}

In the previous sections, we described the formal relationship between standard and visual search LI analogue procedures. It was shown that similar variables have similar effects on both types of tasks. Thus, low- 
and high-schizotypal normals performed similarly on the visual search and standard LI tasks, as did schizophrenic patients and healthy controls. Furthermore, context change and reminder cues had the same effects in both preparations, and performance on the two tasks was significantly correlated. These data support the view that the visual search analogue of LI and standard LI are governed by equivalent processes. Since it is generally accepted that visual search engages attentional processes, it follows that standard LI, at least in part, also requires attentional processing, as has been proposed by several theories (e.g., conditioned attention theory; Lubow, 1989) but discounted by others (e.g., Bouton, 1994; Miller \& Matzel, 1988). The next section will describe the attentional component of a model of target and distractor processing that integrates the data from standard and visual search LI and relates them to dysfunctional attentional processing in schizophrenia. Following this, an attempt will be made to resolve the apparently conflicting features of attentional and response competition theories of LI.

\section{The Attentional Component of Latent Inhibition}

The attentional component of the model is based on the distinction between two modes of information processing: automatic and controlled (Schneider \& Shiffrin, 1977; Shiffrin \& Schneider, 1977), but with an emphasis on the relative strengths of the two processes (cf. Duncan \& Humphreys, 1989; Nakayama, 1990; Treisman, 1993; Wolfe, 1994). At the extremes, automatic processing is relatively rapid, effortless, involuntary, and not available to conscious awareness, whereas controlled processing is relatively slow, serial, effortful, voluntary, and available to conscious awareness. The model will be applied to the preexposure and test stages and to the process of switching from one stage to the other.

Preexposure stage. Figure 1, based on the data from Lubow and Kaplan (1997), presents the mean RTs for correct detection of target presence and target absence as a function of blocks of trials. As can be seen in the left panel, on initial presentations of visual search trials
(Block 1 of preexposure), target and nontarget displays are processed relatively slowly (controlled processing mode), as one would expect with multidimensional complex visual stimuli (e.g., Treisman \& Gelade, 1980). That target search was operating primarily in the controlled mode is indicated by the fact that RTs for targetabsent responses were significantly longer than those for target-present responses, signifying that target search was self-terminating and, therefore, serial.

The left panel of Figure 1 also indicates, as would be expected, that RTs became shorter with repeated presentations of the same targets and distractors. Although not seen in Figure 1, with a sufficiently large number of trials, the target-present and the target-absent RTs should converge, eventually approaching a common asymptotic level, with detection speeds that are close to those associated with pop-out phenomena. Indeed, such effects have been demonstrated for a variety of target/distractor displays (e.g., Ahissar \& Hochstein, 1996; Sireteanu \& Rettenbach, 2000; for a review, see Karni, 1996). Such a pattern would be congruent with a repetition-guided gradual transition from controlled to automatic processing, perhaps reflecting a process by which distractors are converted from individual attention-attracting elements to a coherent but relatively featureless background. This proposal is supported by the facts that target detection time decreases as a function of similarity of distractors to each other (Humphreys, Quinlan, \& Riddoch, 1989; see also Duncan \& Humphreys, 1989) and, under certain conditions, as a function of number of distractors (Bacon \& Egeth, 1991; Banks \& Prinzmetal, 1976; see also Bravo \& Nakayama, 1992, where this effect was present for variable, but not for consistent, mapping conditions). Increasing the number of distractors increases the proximity of distractors. Both proximity and similarity are important factors in promoting grouping (Pomerantz, 1981). Consequently, increasing the number and similarity of distractors may perceptually homogenize these stimuli in such a way that they become a ground, relative to the novel figure. Indeed, the generally longer RTs in schiz-
PREEXPOSURE

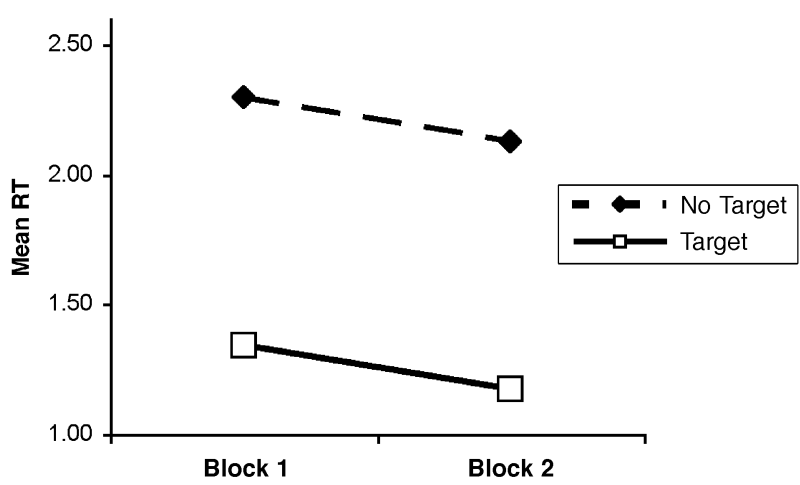

TEST

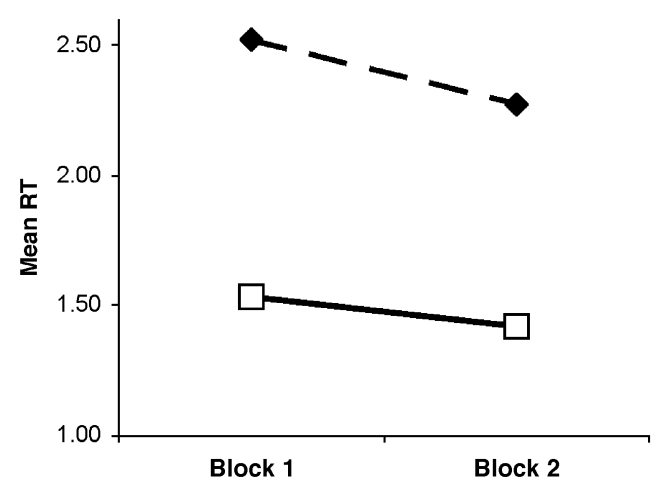

Figure 1. Mean response times (RTs, in seconds) for the detection of the presence or the absence of a unique target among distractors as a function of blocks of trials during the preexposure stage (left panel) and the test stage (right panel). The data are from Lubow and Kaplan (1997). 
ophrenic patients than in normal controls may reflect the former's inability to develop stable representations of context (J. Cohen, Barch, Carter, \& Servan-Schreiber, 1999; J. Cohen \& Servan-Schreiber, 1992; Silverstein, Kovacs, Corry, \& Valone, 2000).

According to the above, the acquisition of efficient target detection depends, at least in part, on achieving automatic processing of the distractors. Indeed, if repeated exposure to the same distractors creates a background condition that supports rapid target detection, then target detection RTs should be considerably shorter with familiar distractors than with novel distractors. Although this perceptual-learning account is supported by a decrease in detection RTs across blocks of trials in the preexposure stage, those data are, of course, confounded with general practice effects. However, there is ample independent evidence that distractor familiarity per se enhances target search performance (e.g., Malinowski \& Hübner, 2000; Reicher, Snyder, \& Richards, 1976; Richards \& Reicher, 1978; Shen \& Reingold, 2001; Wang, Cavanagh, \& Green, 1994). This evidence is supplemented by the data obtained from our own test stage.

Test stage. The test stage contains several sets of data that are relevant to evaluating whether the repeated presentations of the same distractors promote target detection. As has been noted, target detection should be faster in those conditions that contain familiar distractors than in those that contain novel distractors. Although Lubow and Kaplan (1997) found that familiar targets were detected just as quickly against a background of familiar distractors as with novel distractors, $(T \rightarrow T):(D \rightarrow D)$ versus $(\mathrm{T} \rightarrow \mathrm{T}):(\mathrm{N})$, relatively rapid target detection also occurred when a novel target was presented against a background of familiar distractors $(\mathrm{N}):(\mathrm{D} \rightarrow \mathrm{D})$. In addition, when the test stage target and the distractors were both novel (N:N), target detection was severely impaired. As is shown in Figure 1, these findings are consistent across the four 7-condition experiments. These data suggest that target familiarity can overcome the detrimental effects of novel distractors but that distractor familiarity supports efficient detection of novel targets.

Interestingly, if, as we suggested, schizophrenic patients are deficient in their ability to "create ground," as they would be if they are distracted by irrelevant stimuli, they should exhibit smaller NPO effects than those for normals. However, there is nothing in our data to support such a prediction, perhaps because the procedures were not designed for that purpose. On the other hand, BraunsteinBercovitz (2003) reported that standard LI is attenuated in field-independent, as compared with field-dependent, individuals, as well as in high, as compared with low, schizotypals, although schizotypality and field dependence were not correlated. Relatedly, Uhlhaas, Silverstein, Phillips, and Lovell (2004) found impaired processing of visual context in high schizotypals with thought disorder (but see Tsakanikos \& Reed, 2003). 6

\section{Switching From Automatic to Controlled Processing and Normal LI}

By the end of the preexposure stage, the normal subject's visual search has moved from the fully controlled mode toward increased automaticity. In the test phase, when trials are introduced with new combinations of old targets and distractors, as well as with new targets and distractors, the mapping conditions become unstable, and efficient performance (i.e., maintaining a low error rate) requires reverting to a controlled processing mode. The switch in the weights of automatic and controlled

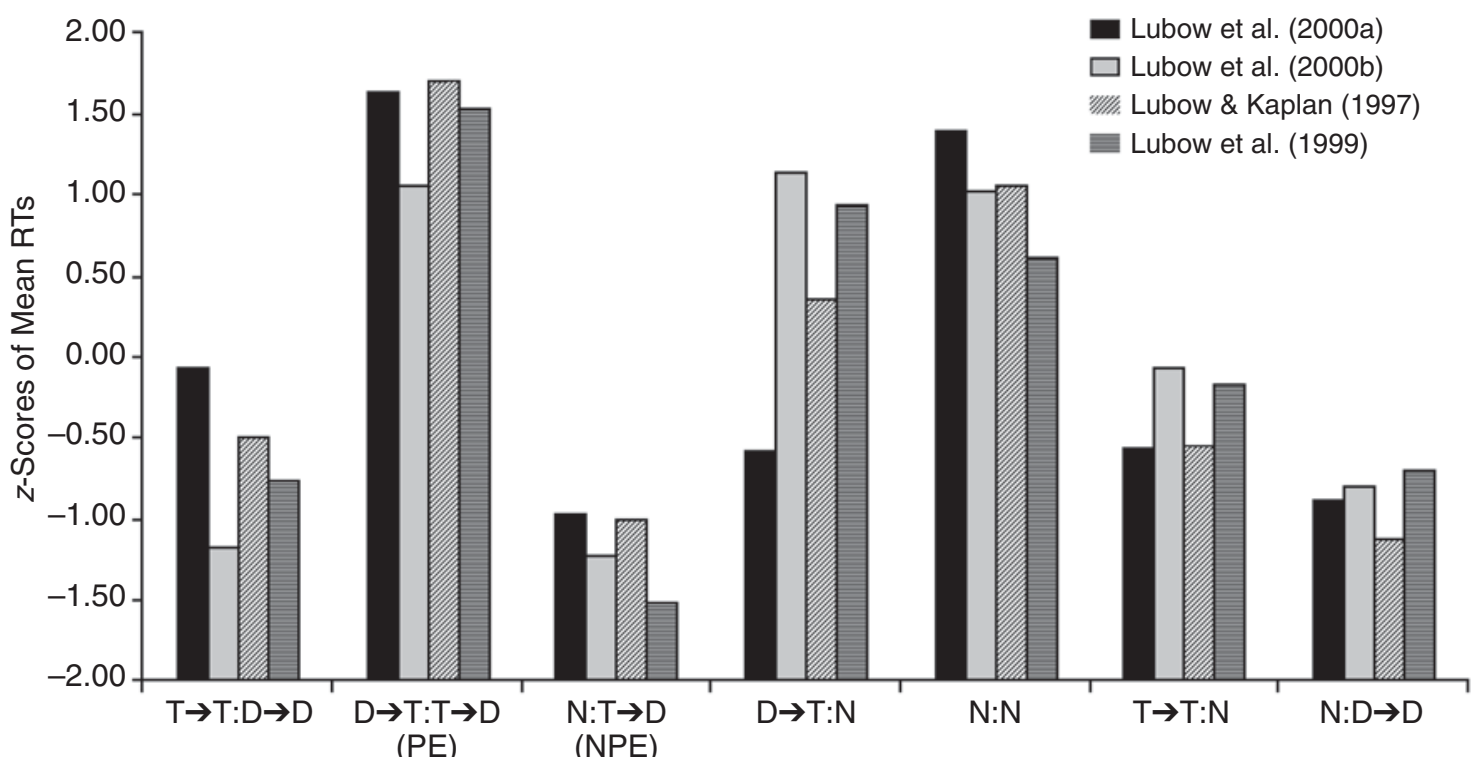

Figure 2. Mean target detection response times (RTs, in seconds), converted to $z$ scores, for the seven test conditions in the four experiments listed in Table 2. 
processing, from relatively automatic at the end of the preexposure phase to more controlled at the beginning of the test stage, can be seen in Figure 2, where RTs in the first block of trials in the test stage are elevated, as compared with the last block of the preexposure stage.

The visual search LI effect-slower target detection in the PE than in the NPE condition - can be accounted for by postulating that the relatively unattended preexposure to the distractor stimulus creates a stimulus-specific bias against the transfer from automatic to controlled processing modes when these previous distractor stimuli reappear as targets in the test stage. Thus, when the switch is made from the end of the preexposure phase to the control-demanding test phase, those test trials that contain targets that were distractors in the preexposure phase will be responded to more slowly than those trials that have novel targets, thereby providing the visual search analogue of LI. Such a proposal has been presented in CAT as the conditioning of inattention (Lubow, 1989; Lubow \& Gewirtz, 1995; for a review of empirical support, see Lubow, 2005).

\section{Disrupted LI in Schizophrenic Patients and High-Schizotypal Normals}

This model will now be applied to schizophrenic patients who exhibit attenuated LI in standard and visual search LI analogue procedures and whose selective attention impairment has been characterized by high distractibility (e.g., Anscombe, 1987; Braff, 1993; Nuechterlein \& Dawson, 1984). Figures 3 and 4 present preexposure and test stage RTs, collapsed across conditions, as a function of blocks, for groups of schizophrenic patients and normal subjects (E. Cohen et al., 2004; Lubow, Kaplan, et al., 2000). As can be seen, patient groups responded more slowly than their matched normal controls, in both the preexposure and the test stages. Indeed, patients responded more slowly than controls across all trial types. Although this pattern of data may be due to the inability of the schizophrenic patients to form stable contexts, such slow responding also is present in a variety of other preparations (e.g., Vinogradov, Poole, Willis-Shore, Ober, \& Shenaut, 1998; for reviews, see Nuechterlein, 1977; Schatz, 1998;
Steffy \& Waldman, 1993) and probably represents a general deficit condition.

A comparison of the left and the right panels in Figures 3 and 4 also indicates that detection RTs for patient and control groups were longer in the test stage than in the preexposure stage, as would be expected with the more difficult test stage task (the test stage had many more trial types than the preexposure stage did). However, patients, as compared with controls, exhibited a disproportionate elevation of RTs from preexposure to test stages, perhaps reflecting a generally increased sensitivity to task load by the patients (cf. Nuechterlein \& Dawson, 1984).

In regard to LI, the hypothesis that high-schizotypal normals and some subgroups of schizophrenic patients are impaired in their ability to convert normally irrelevant stimuli into background context remains viable. These groups, slow to benefit from display repetitions that, for normals, produce the transfer from controlled to automatic processing, continue to show relatively controlled visual search during the course of the preexposure stage. However, it must be noted that these tentative conclusions are based on a limited sample of patients with heterogeneous symptoms and histories. Indeed, the data indicate that there are modulating effects of variables, such as sex and symptom composition. As can be seen in Table 5, male schizophrenics show more LI than do controls, and female schizophrenics show less LI than do controls. A similar pattern with low and high schizotypals also has been reported for RT in a more traditional LI task (Lubow \& De la Casa, 2002). Furthermore, schizophrenic patients grouped according to combinations of positive and negative symptoms (independently of sex) indicates that patients with high levels of negative symptoms and low levels of positive symptoms actually displayed a super-LI effect, as compared with healthy controls (E. Cohen et al., 2004).

Nevertheless, those subgroups that do exhibit attenuated LI can be described as being relatively slow in making the transition from an automatic to a controlled mode of information processing. Although this may reflect a general switching problem (Weiner, 2003; Weiner \& Fel-
PREEXPOSURE

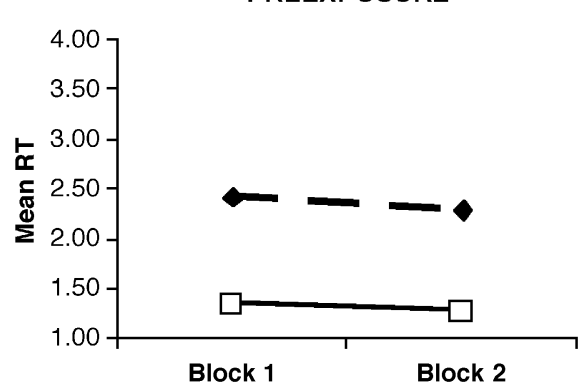

TEST

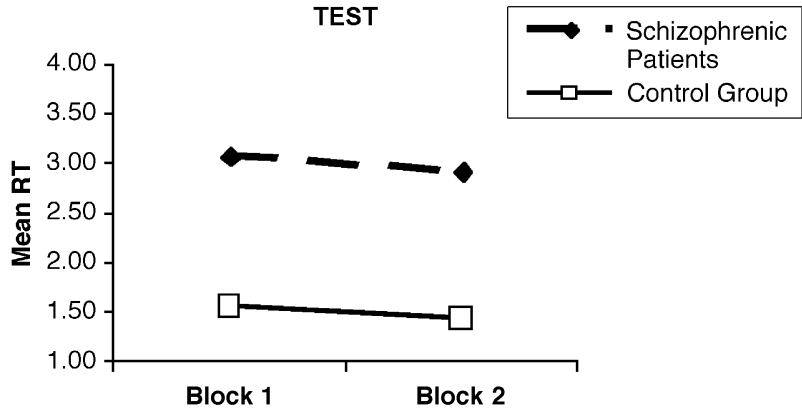

Figure 3. Mean target detection response times (RTs, in seconds) for schizophrenic patient and matched control groups as a function of blocks of trials during preexposure and test stages. The data are from E. Cohen et al. (2004). 

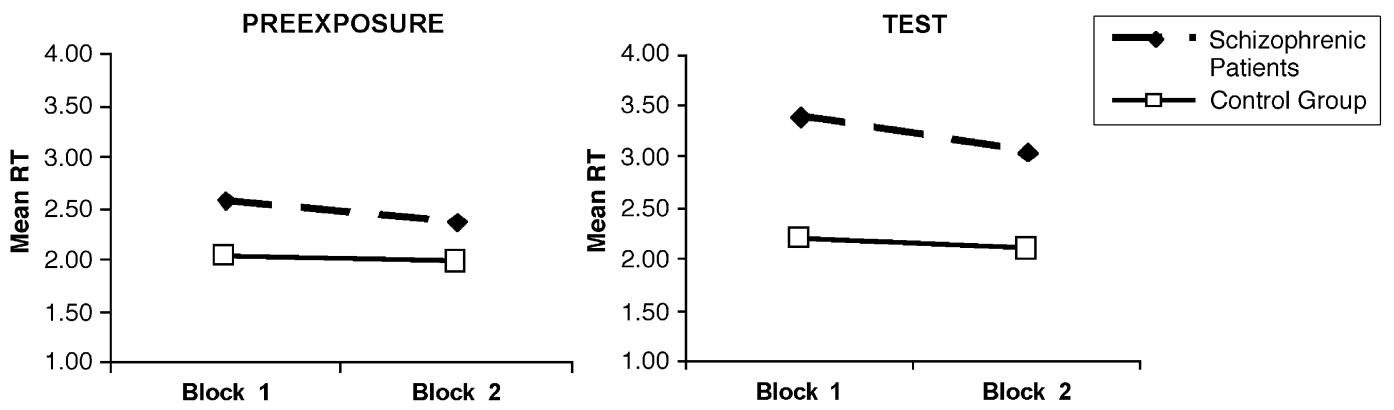

Figure 4. Mean target detection response times (RTs, in seconds) for schizophrenic patient and matched control groups as a function of blocks of trials during preexposure and test stages. The data are from Lubow, Kaplan, Abramovich, Rudnick, and Laor (2000).

don, 1997), we would maintain that the switching deficit is specific to automatic processing (Lubow \& Gewirtz, 1995). Specifically, normal LI is dependent on the acquisition of automatic processing of the irrelevant preexposed stimulus, such that the nominally unattended stimuli are eventually processed effortlessly, rapidly, autonomously (reflexively), and in such a way that they are unavailable to conscious awareness (Logan, 1988). The attenuated LI in high schizotypals and schizophrenic patients, as compared with low schizotypals and normal subjects, is a consequence of the preexposed irrelevant stimuli continuing to engage the controlled processing mode. In other words, for schizophrenic subjects, even with continued practice in the preexposure phase, attention continues to be captured by the irrelevant stimuli. As a consequence, conscious awareness is inundated with experimentally familiar but phenomenally novel stimuli. As has been described by Frith (1979), the schizophrenic has difficulty in limiting the contents of consciousness. Indeed, the positive symptoms of schizophrenia are congruent with the notion that, for schizophrenics, short-term memory is "preoccupied" with irrelevant stimuli. Indeed, when high-schizotypals exhibit less LI than lowschizotypals do, they also have superior recall and recognition memory scores for the preexposed irrelevant stimuli, indicating that the attenuation of LI in the highschizotypal subjects was a result of increased controlled processing of the irrelevant preexposed stimuli (De la Casa, Ruiz, \& Lubow, 1993).

This analysis suggests that researchers of psychoticprone normals and schizophrenic patient populations should examine performance on tasks in which the roles of automatic and controlled information processing are clearly delineated and in which success depends on the presence/absence of one or the other. In addition, theoretically motivated tasks should be developed in which support for a particular hypothesis would be reflected in better, rather than poorer, performance by the pathologic than by the control group (Spring \& Zubin, 1978). LI and related procedures meet this criterion. In standard LI studies, high-schizotypal subjects and schizophrenic patients show better associative learning to a previously exposed irrelevant stimulus than do their normal counterparts.

\section{Implications of the Visual Search Data for Theories of $\mathbf{L I}$}

As has already been noted, explanations of LI effects fall into two general categories: attentional decline/ acquisition failure (A-theories; e.g., Lubow et al., 1981; Mackintosh, 1975; Pearce \& Hall, 1980; Wagner, 1981) and retrieval-based competition (R-theories; e.g., Bouton, 1993, 1994; Miller et al., 1986; Miller \& Matzel, 1988). A-theories assume that passive, inconsequential stimulus preexposure decreases attention (salience) to that stimulus, one consequence of which is a reduction in the ability of the stimulus to enter into new associations. As opposed to A-theories, R-theories propose that LI results from a retrieval-based competition between associations learned in the preexposure phase $\mathrm{CS}-0$ (i.e., CSno-consequence) and in the acquisition phase (CS-US), the latter of which has not been affected by preexposure to the CS.

Support for the R-theory account of LI comes primarily from three sources: (1) animal experiments in which the time between the acquisition and the test phases of three-stage paradigms has been increased and reduced LI has been shown, (2) experiments in which reminder treatments of the preexposure phase, administered before or during the test stage have been used and increased LI has been shown, and (3) experiments in which the context has been changed from preexposure to acquisition or test and reduced LI has been reported. Accordingly, R-theorists hold that if one varies the time between acquisition and test (or between preexposure and acquisition) and LI is found after a short delay, but not after a long one, this is presumptive evidence that with

Table 5

Latent Inhibition Scores, $($ PE - NPE)/NPE, from Two Studies with Schizophrenic (Schiz) and Normal Groups and One With High- and Low-Schizotypal Normals

\begin{tabular}{lcccccccc}
\hline & \multicolumn{2}{c}{$\begin{array}{c}\text { Lubow, Kaplan, } \\
\text { et al. (2000) }\end{array}$} & & \multicolumn{2}{c}{$\begin{array}{c}\text { E. Cohen et al. } \\
(2004)\end{array}$} & & \multicolumn{2}{c}{$\begin{array}{c}\text { Lubow, Kaplan, \& } \\
\text { De la Casa (2001) }\end{array}$} \\
\cline { 2 - 3 } Gender & Schiz & Control & & Schiz & Control & & High & Low \\
\hline Male & .12 & .07 & & .25 & .06 & & .21 & .13 \\
Female & .03 & .17 & & .22 & .19 & & .06 & .17 \\
\hline
\end{tabular}


the short delay the CS-US association was acquired, but not manifest, and that something occurred during the longer delay that allowed the normally associated CS-US event from the acquisition phase to be retrieved (for a review of this literature, see Lubow \& De la Casa, in press). A similar logic has been used by R-theorists to interpret evidence that the presentation of a reminder stimulus before test alleviates the otherwise expected retarded learning (Kasprow et al., 1984; Killcross \& Dickinson, 1996) and the fact that context change disrupts LI (e.g., Westbrook et al., 2000; Zalstein-Orda \& Lubow, 1995).

Support for the A-theories of LI comes from several sources. (1) LI has been obtained with two-stage procedures, in which the second stage is both CS-US acquisition and test. Furthermore, in many cases of two-stage LI, the LI effect appears from Trial 1 onward (for a review, see Lubow, 1989), which, again, suggests reduced associability of the preexposed stimulus. (2) Inconsequential preexposure of a stimulus can produce LI after pairing with either an appetitive or an aversive event. (3) Similarly, LI can be obtained when the same preexposed stimulus is subsequently trained as either a conditioned excitor or a conditioned inhibitor (the preexposed stimulus signals the absence of a reinforcer; see, e.g., Best, 1975; Halgren, 1974; Reiss \& Wagner, 1972; Rescorla, 1971). "It seems awkward to suppose that preexposure changes such an array of separate, and conflicting, associative strengths" (Rescorla, 2002, p. 370, italics added). (4) In a study in which LI was examined with a procedure designed to differentiate between initial associative strength and retardation of the acquisition of associative strength (associability), stimulus preexposure affected the rate of subsequent associative learning, but not the initial associative strength. This "supports the common interpretation that latent inhibition involves the reduction in salience of a stimulus, slowing any associative learning in which it is subsequently asked to engage" (Rescorla, 2002, p. 376).

Much of the controversy between the A- and the Rtheories derives from the fact that data upholding the former were obtained from either two-stage procedures or three-stage procedures that conceptualized the thirdstage test performance as a mere reflection of Stage 2 associative strength. On the other hand, data that support $\mathrm{R}$-theories come primarily from three-stage procedures in which the few Stage 2 CS-US pairing trials are conducted off baseline, so that there is no direct measure of conditioned response acquisition (as in conditioned taste aversion and conditioned suppression protocols). The Stage 3 test performance is assumed to be the result of an interaction between associations acquired in Stage 1 and Stage 2, with the latter being unaffected by the former.

However, LI cannot be accounted for by appealing independently to either one or the other theoretical approach. On the one hand, LI can be generated in a two-stage procedure, with the LI effect appearing at the beginning of the second stage. This indicates that some difference be- tween PE and NPE groups must have been acquired during the Stage 1 stimulus preexposure. On the other hand, such a demonstration of LI is disrupted if the preexposure and acquisition test phases are conducted in different contexts. Since the subject in the preexposure phase has no knowledge of the forthcoming acquisition test context, the context-same and the context-different groups cannot differ from each other until the context manipulation in Stage 2. It would appear, then, that although normal LI may be explained primarily through processes occurring in the stimulus preexposure stage (A-theory), the attenuation of LI requires some additional explanatory constructs (R-theory).

The visual search LI data make this assessment quite clear even within the confines of a two-stage procedure. Since reminder and context effects have been used to promote a retrieval/competition account of LI, our demonstrations that these variables also modulate attentionally based visual search LI indicates that such effects are not exclusively favorable to retrieval theories of LI, at least as currently formulated; they are also congruent with an attentional interpretation of LI. The apparent opposition between the positions can be resolved by noting that although A-theories rely on attentional constructs, they also contain a staged serial-processing component, such that the effect of the decreased attention that was acquired in the stimulus preexposure stage impedes the acquisition of the new association in the subsequent stage, when the preexposed stimulus is paired with a US. On the other hand, R-theories, with their emphasis on competition processes, eschew the processing-by-stages approach. In addition, they ignore the role of stimulusspecific attention. Given the type of data reported in the present set of experiments, as well as in more traditional LI studies, it would appear that a viable theory of stimulus preexposure effects will have to incorporate both attentional and competition constructs, most likely with an iterative recycling process by which attention affects competition, which in turn affects attention.

A theory of LI, then, must incorporate not only a postulate that allows for different stimulus preexposure conditions (e.g., PE and NPE) to produce different effects, but also one that allows for the same stimulus preexposure conditions to produce different test-dependent effects. The two sets of variables correspond to those that are manipulated during the preexposure stage and modulate the acquisition of LI (e.g., number and duration of stimulus preexposures) and those that are manipulated after the preexposure stage and correspond to a modulation of normal LI (e.g., context change and retention interval). The two accounts of traditional LI can be reconciled by noting that, as a rule, the effects of the preexposure stage variables map onto A-theories and the effects of the postpreexposure stage variables map onto R-theories. This conclusion is supported by data from both standard and visual search analogue LI experiments, thereby also reinforcing our initial contention that these two paradigms 
tap similar processes. However, the new understanding is that these similar processes are at least two in number. One consequence of considering LI to be generated by multiple processes is that it may be necessary to reconsider the sources of LI aberrations in high-schizotypal normals and schizophrenic patients.

\section{SUMMARY AND CONCLUSIONS}

We have demonstrated that preexposure of a shape as a distractor interferes with its subsequent ability to act as a target. This stimulus preexposure effect was obtained with several variations of a procedure in which subjects were required to detect a unique target among a large set of homogeneous distractors. RTs to such targets were longer than those to new targets or to previously presented targets. In particular, the two conditions, $(\mathrm{D} \rightarrow \mathrm{T}):(\mathrm{T} \rightarrow \mathrm{D})$ and $(\mathrm{N}):(\mathrm{T} \rightarrow \mathrm{D})$, that provide a formal analogue for the traditional LI conditions, PE and NPE, elicited responses that are congruent with the position that such preexposures produce a stimulus-specific attentional decline. The robust LI-like effect was present when the two critical conditions were embedded in within-subjects designs with seven or fewer additional conditions, with a procedure that required identifying presence versus absence of a target and with a procedure in which the target was present on every trial but the subject had to indicate whether it was on the right or the left side of the screen. It was also shown that the same variables have similar effects in both standard and visual search LI preparations. Thus, both traditional LI and visual search LI are reduced when there is a change of context from preexposure to test phases and when there are no reminder trials in the test. Individual difference variables also produced the same effects in both preparations. Schizophrenic patients, as compared with normal controls, and high-schizotypal normals, as compared with low-schizotypal normals, displayed attenuated standard LI and visual search LI effects. Furthermore, in both cases, these effects interacted with gender.

Together, then, these findings encourage the following conclusions. (1) The processes that underlie target detection with LI-like visual search conditions are the same as those that subserve traditional LI in animals and humans. (2) These processes, although attentional, are modulated by reminder trial and context manipulations. (3) Any manipulation that promotes the similarity of a preexposure session, in which there is a relatively unattended irrelevant stimulus that will later become a relevant target stimulus, and the test session will increase LI. (4) Attentional and retrieval accounts of LI are not necessarily incompatible; the former is best applied to the effects of variables manipulated in the stimulus preexposure stage, and the latter to poststimulus preexposure manipulations. (5) Given that both A- and R-processes are involved in LI, it remains to be shown which one is responsible for LI aberrations in schizophrenic patients and high-schizotypal normals.

\section{REFERENCES}

AgID, Y. (1991). Parkinson's disease: Pathophysiology. Lancet, 337, 1321-1324.

AHISSAR, M., \& Hochstein, S. (1996). Learning pop-out detection: Specificities to stimulus characteristics. Vision Research, 21, 3487-3500.

Anscombe, F. (1987). The disorder of consciousness in schizophrenia. Schizophrenia Bulletin, 13, 241-260.

BACON, W., \& EGETH, H. (1991). Local processes in preattentive feature detection. Journal of Experimental Psychology: Human Perception \& Performance, 17, 77-90.

BANKS, W. P., \& PRINZMETAL, W. (1976). Configurational effects in visual information processing. Perception \& Psychophysics, 19, 361-367.

Baruch, I., Hemsley, D. R., \& Gray, J. A. (1988a). Differential performance of acute and chronic schizophrenics in a latent inhibition task. Journal of Nervous \& Mental Disease, 176, 598-606.

Baruch, I., Hemsley, D. R., \& Gray, J. A. (1988b). Latent inhibition and "psychotic proneness" in normal subjects. Personality \& Individual Differences, 9, 777-784.

BennetT, C. H., Maldonado, A., \& Mackintosh, N. J. (1995). Learned irrelevance is not the sum of exposure to CS and US. Quarterly Journal of Experimental Psychology, 48B, 117-128.

Best, M. R. (1975). Conditioned and latent inhibition in taste aversion learning: Clarifying the role of learned safety. Journal of Experimental Psychology: Animal Behavior Processes, 104, 97-113.

BonARDI, C., \& HALl, G. (1996). Learned irrelevance: No more than the sum of CS and US preexposure effects? Journal of Experimental Psychology: Animal Behavior Processes, 22, 183-191.

Bouton, M. E. (1993). Context, time, and memory retrieval in the interference paradigms of Pavlovian conditioning. Psychological Bulletin, 114, 80-99.

Bouton, M. E. (1994). Conditioning, remembering, and forgetting. Journal of Experimental Psychology: Animal Behavior Processes, 20, 219-231.

Bouton, M. E., \& Brooks, D. C. (1993). Time and context effects on performance in a Pavlovian discrimination. Journal of Experimental Psychology: Animal Behavior Processes, 19, 165-179.

Bouton, M. E., Nelson, J. B., \& Rosas, J. M. (1999). Stimulus generalization, context change, and forgetting. Psychological Bulletin, 125, 171-186.

BRAFF, D. L. (1993). Information processing and attention dysfunctions in schizophrenia. Schizophrenia Bulletin, 19, 233-259.

Braunstein-Bercovitz, H. (2000). Is the attentional dysfunction in schizotypy related to anxiety? Schizophrenia Research, 46, 255-267.

BraunsteIn-Bercovitz, H. (2003). The modulation of latent inhibition by field-dependency: Is it related to the attentional dysfunction in schizotypy? Personality \& Individual Differences, 35, 1719-1729.

Braunstein-Bercovitz, H., Dimentman-Ashkenazi, I., \& Lubow, R. E. (2001). Stress affects the selection of relevant from irrelevant stimuli. Emotion, 1, 182-192.

Braunstein-Bercovitz, H., Hen, I., \& Lubow, R. E. (2004). Masking task load modulates latent inhibition: Support for a distraction model of irrelevant information processing by high schizotypal and anxious participants. Cognition \& Emotion, 18, 1135-1144.

Braunstein-Bercovitz, H., \& Lubow, R. E. (1998a). Are highschizotypal normal participants distractible or limited in attentional resources? A study of latent inhibition as a function of masking task load and schizotypy level. Journal of Abnormal Psychology, 107, 659-670.

BrAUNSTEIN-Bercovitz, H., \& Lubow, R. E. (1998b). Latent inhibition as a function of the modulation of attention to the preexposed irrelevant stimulus. Learning \& Motivation, 29, 261-279.

Braunstein-Bercovitz, H., Rammsayer, T., GibBons, H., \& Lubow, R. E. (2002). Latent inhibition deficits in high-schizotypal normals: Symptom-specific or anxiety-related? A review. Schizophrenia Research, 53, 109-121.

BRAVO, M. J., \& NAKAYAMA, K. (1992). The role of attention in different visual-search tasks. Perception \& Psychophysics, 51, 465-472.

Cantor, G. N. (1969). Stimulus familiarization effect and the change effect in children's motor task behavior. Psychological Bulletin, 71, 144-160. 
Carson, S., Peterson, J. B., \& Higgins, D. M. (2003). Decreased latent inhibition is associated with increased creative achievement in high-functioning individuals. Journal of Personality \& Social Psychology, 85, 499-506.

CLARIDGe, G. (1985). Origins of mental illness. Oxford: Blackwell.

Claridge, G., \& Broks, P. (1984). Schizotypy and hemisphere function: I. Theoretical considerations and the measurement of schizotypy. Personality \& Individual Differences, 5, 633-648.

Cohen, E., Sereni, N., Kaplan, O., Weizman, A., Kikinzon, L., WeIner, I., \& Lubow, R. E. (2004). The relation between latent inhibition and symptom-types in young schizophrenics. Behavioural \& Brain Research, 149, 113-122.

COHEN, J., Barch, D. M., CARTER, C., \& Servan-Schreiber, D. (1999). Context-processing deficits in schizophrenia: Converging evidence from three theoretically motivated cognitive tasks. Journal of Abnormal Psychology, 108, 120-133.

COHEN, J., \& SERVAN-SCHREIBER, D. (1992). Context, cortex, and dopamine: A connectionist approach to behavior and biology in schizophrenia. Psychological Review, 99, 45-77.

De La CASA, L. G., \& LUBOW, R. E. (2001). Latent inhibition with a response time measure from a within-subject design: Effects of number of preexposures, masking task, context change, and delay. Neuropsychology, 15, 244-253.

De la Casa, L. G., RuIZ, G., \& Lubow, R. E. (1993). Latent inhibition and recall/recognition of irrelevant stimuli as a function of preexposure duration in high and low psychotic-prone subjects. British Journal of Psychology, 84, 119-132.

Della CASA, V., HöFer, I., \& Feldon, J. (1999). Latent inhibition in smokers vs. nonsmokers: Interaction with number or intensity of preexposures? Pharmacology Biochemistry \& Behavior, 62, 353-359.

Duncan, J., \& HumPhreYs, G. W. (1989). Visual search and stimulus similarity. Psychological Review, 96, 433-458

Escobar, M., ARCEDIANO, F., \& Miller, R. R. (2003). Latent inhibition in human adults without masking. Journal of Experimental Psychology: Learning, Memory, \& Cognition, 29, 1028-1040.

Escobar, M., Oberling, P., \& Miller, R. R. (2002). Associative deficit accounts of disrupted latent inhibition and blocking in schizophrenia. Neuroscience \& Biobehavioral Reviews, 26, 203-216.

EySENCK, H. J., \& EYSENCK, S. B. G. (1976). Psychoticism as a dimension of personality. London: Hodder \& Stoughton.

Feldon, J., \& Weiner, I. (1989). Abolition of the acquisition but not the expression of latent inhibition by chlordiazepoxide in rats. Pharmacology Biochemistry \& Behavior, 32, 123-127.

FRITH, C. D. (1979). Consciousness, information processing, and schizophrenia. British Journal of Psychiatry, 134, 225-235.

GIBB, W. R. G. (1991). Neuropathology of the substantia nigra. European Neurology, 31, 48-59.

GiBbons, H., RAMmSAYER, T. H., \& Lubow, R. E. (2001). Latent inhibition depends on inhibitory attentional learning to the preexposed stimulus: Evidence from visual search and rule-learning tasks. Learning \& Motivation, 32, 457-476.

GiBSON, E. J. (1969). Principles of perceptual learning and development. New York: Appleton-Century-Crofts.

Golosheiken, S. A., Volf, N. V., \& Razumnikova, O. M. (1997). Significance of laterality and sex in the processes of selective attention. Zhurnal Vysshei Nervnoi Deyatelnosti Imeni I. P. Pavlova, 47, 740-742.

GrAY, J. A. (1995). Dopamine release in the nucleus accumbens: The perspective from aberrations of consciousness in schizophrenia. Neuropsychologia, 33, 1143-1153.

GRAY, J. A. (1998). Integrating schizophrenia. Schizophrenia Bulletin, 24, 249-266.

Gray, J. A., Feldon, J., Rawlins, J. N. P., Hemsley, D. R., \& Smith, A. D. (1991). The neuropsychology of schizophrenia. Behavioral \& Brain Sciences, 14, 1-84.

Gray, N. S., Fernandez, M., Williams, J., Ruddle, R. A., \& SnowDEN, R. J. (2002). Which schizotypal dimensions abolish latent inhibition? British Journal of Clinical Psychology, 41, 271-284.

Gray, N. S., HemsLeY, D. R., \& GraY, J. A. (1992). Abolition of latent inhibition in acute, but not chronic, schizophrenics. Neurology, Psychiatry \& Brain Research, 1, 83-89.
Gray, N. S., Pickering, A. D., Hemsley, D. R., Dawling, S., \& Gray, J. A. (1992). Abolition of latent inhibition by a single $5 \mathrm{mg}$ dose of $d$-amphetamine in man. Psychopharmacology, 107, 425-430.

Gray, N. S., Pilowsky, L. S., Gray, J. A., \& Kerwin, R. W. (1995). Latent inhibition in drug-naive schizophrenics: Relationship to duration of illness and dopamine D2 binding using SPET. Schizophrenia Research, 17, 95-107.

Gray, N. S., Williams, J., Fernandez, M., Ruddle, R. A., Good, M. A., \& SNOWDON, R. J. (2001). Context dependent latent inhibition in adult humans. Quarterly Journal of Experimental Psychology, 54B, 233-245.

Gruzelier, J. H. (1996). The factorial structure of schizotypy: Part I. Affinities with syndromes of schizophrenia. Schizophrenia Bulletin, 22, 611-620.

GRUZELIER, J. H., \& DoIG, A. (1996). The factorial structure of schizotypy: Part II. Cognitive asymmetry, arousal, handedness, and sex. Schizophrenia Bulletin, 22, 621-634.

Guterman, Y., Josiassen, R., Bashore, R. E., Johnson, M., \& Lubow, R. E. (1996). Latent inhibition effects reflected in eventrelated brain potentials in healthy controls and schizophrenics. Schizophrenia Research, 20, 315-326.

HALGREN, C. R. (1974). Latent inhibition in rats: Associative or nonassociative? Journal of Comparative \& Physiological Psychology, 86, 74-78.

Hall, G. (1991). Perceptual and associative learning. Oxford: Oxford University Press, Clarendon Press.

Hellman, P. A., Crider, A., \& Solomon, P. R. (1983). Interaction of tail-pressure stress and $d$-amphetamine in disruption of the rat's ability to ignore an irrelevant stimulus. Behavioral Neuroscience, 97, 1017-1021

HEMSLEY, D. R. (1987). An experimental psychological model for schizophrenia. In H. Häfner, W. F. Gattaz, \& W. Janzarik (Eds.), Search for the causes of schizophrenia (pp. 179-188). Berlin: Springer-Verlag.

Humphreys, G. W., Quinlan, P. T., \& RidDOCH, M. J. (1989). Grouping processes in visual search: Effects with single- and combinedfeature targets. Journal of Experimental Psychology: General, 118, 258-279.

JoHNSTON, W. A., \& Hawley, K. J. (1994). Perceptual inhibition of expected inputs: The key that opens closed minds. Psychonomic Bulletin \& Review, 1, 56-72.

Joseph, M. H., Datla, K., \& Young, A. M. J. (2003). The interpretation of the measurement of nucleus accumbens dopamine by in vivo dialysis: The kick, the craving or the cognition? Neuroscience \& Biobehavioral Reviews, 27, 527-541.

Joseph, M. H., Peters, S. L., Moran, P. M., Grigoryan, G. A., Young, A. M. J., \& GraY, J. A. (2000). Modulation of latent inhibition in the rat by altered dopamine transmission in the nucleus accumbens at the time of conditioning. Neuroscience, 101, 921-930.

KANE, J. M. (1995). Dosing issues and depot medication in the maintenance treatment of schizophrenia. International Clinical Psychopharmacology, 10, 65-71.

KAPLAN, O., \& LubOW, R. E. (2001). Context and reminder effects in a visual search analog of latent inhibition. Learning \& Motivation, 32, 137-153.

KARNI, A. (1996). The acquisition of perceptual and motor skills: A memory system in the human cortex. Cognitive Brain Research, $\mathbf{5}$, 39-48.

Kasprow, W. J., Catterson, D., Schachtman, T. R., \& Miller, R. R. (1984). Attenuation of latent inhibition by post-acquisition reminder. Quarterly Journal of Experimental Psychology, 36B, 53-63.

Kathmann, N., von Recum, S., HaAg, C., \& Engel, R. R. (2000). Electrophysiological evidence for reduced latent inhibition in schizophrenic patients. Schizophrenia Research, 45, 103-114.

KILlCross, S., \& DickINSON, A. (1996). Contextual control of latent inhibition by the reinforcer. Quarterly Journal of Experimental Psychology, 49B, 45-59.

Kumari, V., Cotter, P. A., Mulligan, O. F., Checkley, S. A., Gray, N. S., Hemsley, D. R., Thornton, J. C., Corr, P. J., Toone, B. K., \& GRAY, J. A. (1999). Effects of $d$-amphetamine and haloperidol on 
latent inhibition in healthy male volunteers. Journal of Psychopharmacology, 13, 398-405.

Lacroix, L., Spinelli, S., Broersen, L. M., \& Feldon, J. (2000). Blockade of latent inhibition following pharmacological increase or decrease of GABA-sub(A) transmission. Pharmacology Biochemistry \& Behavior, 66, 893-901.

LAWRENCE, D. H. (1949). The acquired distinctiveness of cues: I. Transfer between discriminations on the basis of familiarity with the stimulus. Journal of Experimental Psychology, 39, 770-784.

LehmanN, J., StöHR, T., \& FeldON, J. (2000). Long-term effects of prenatal stress experience and postnatal maternal separation on emotionality and attentional processes. Behavioural Brain Research, 107, 133-144.

Leumann, L., Feldon, J., Vollenweider, F. X., \& Ludewig, K. (2002). Effects of typical and atypical antipsychotics on prepulse inhibition and latent inhibition in chronic schizophrenia. Biological Psychiatry, 52, 729-739.

LiPP, O. V., SIDDLE, D. A. T., \& ARNOLD, S. L. (1994). Psychosis-proneness in a non-clinical sample: II. A multi-experimental study of "attentional malfunctioning." Personality \& Individual Differences, 17, 405-424.

LIPP, O. V., \& VAITL, D. (1992). Latent inhibition in human Pavlovian differential conditioning: Effect of additional stimulation after preexposure and relation to schizotypal traits. Personality \& Individual Differences, 13, 1003-1012.

LoGAN, G. D. (1988). Toward an instance theory of automatization. Psychological Review, 95, 492-527.

LUBOW, R. E. (1989). Latent inhibition and conditioned attention theory. New York: Cambridge University Press.

LuBOw, R. E. (1997). Latent inhibition as a measure of learned inattention: Some problems and solutions. Behavioural Brain Research, 88, 75-83.

LuBow, R. E. (2005). The construct validity of the animal-latent inhibition model of selective attention deficits in schizophrenia. Schizophrenia Bulletin, 31, 139-153.

LUBOW, R. E., \& DE LA CASA, L. G. (2002). Latent inhibition as a function of schizotypality and gender: Implications for schizophrenia. $\mathrm{Bi}$ ological Psychology, 59, 69-86.

LuBOW, R. E., \& DE LA CASA, L. G. (in press). There is a time and a place for everything: Bi-directional modulations of latent inhibition by time-induced context differentiation. Psychonomic Bulletin \& Review.

Lubow, R. E., Dressler, R., \& Kaplan, O. (1999). The effects of target and distractor familiarity on visual search in de novo Parkinson's disease patients: Latent inhibition and novel pop-out. Neuropsychology, 13, 415-423.

LuBOW, R. E., \& GewIRTZ, J. C. (1995). Latent inhibition in humans: Data, theory, and implications for schizophrenia. Psychological Bulletin, 117, 87-103.

LUBOW, R. E., \& Josman, Z. E. (1993). Latent inhibition deficits in hyperactive children. Journal of Child Psychiatry \& Psychology, 34, 959-973.

LUBOW, R. E., \& KAPLAN, O. (1997). Visual search as a function of type of prior experience with target and distractor. Journal of Experimental Psychology: Human Perception \& Performance, 23, 14-24.

Lubow, R. E., Kaplan, O., Abramovich, P., RudNick, A., \& LAOR, N. (2000). Visual search in schizophrenia: Latent inhibition and novel pop-out effects. Schizophrenia Research, 45, 145-156.

Lubow, R. E., KaPlan, O., \& De la CASA, L. G. (2001). Performance on the visual search analog of latent inhibition is modulated by an interaction between schizotypy and gender. Schizophrenia Research, 52, 275-287.

Lubow, R. E., Toren, P., LaOr, N., \& Kaplan, O. (2000). The effects of target and distractor familiarity on visual search in anxious children: Latent inhibition and novel pop-out. Journal of Anxiety Disorders, 14, 41-56.

LuBOW, R. E., WeInER, I., \& Schnur, P. (1981). Conditioned attention theory. In G. H. Bower (Ed.), The psychology of learning and motivation (Vol. 15, pp. 1-49). San Diego: Academic Press.

Mackintosh, N. J. (1975). A theory of attention: Variations in the associability of stimuli with reinforcement. Psychological Review, 82, 276-284.
Malinowski, P., \& Hübner, R. (2000). The effect of familiarity on visual-search performance: Evidence for learned basic features. Perception \& Psychophysics, 63, 458-463.

MARSDEN, C. D. (1994). Problems with long-term levodopa therapy for Parkinson's disease. Clinical Neuropharmacology, 17(Suppl. 2), S32-S44.

Martins Serra, A., Jones, S. H., Toone, B., \& Gray, J. A. (2001). Impaired associative learning in chronic schizophrenics and their firstdegree relatives: A study of latent inhibition and the Kamin blocking effect. Schizophrenia Research, 48, 273-289.

Matzel, L. D., SchachtMAn, T. R., \& Miller, R. R. (1988). Learned irrelevance exceeds the sum of CS-preexposure and US-preexposure deficits. Journal of Experimental Psychology: Animal Behavior Processes, 14,311-319.

McLaren, I. P. L., Bennett, C., Plaisted, K., Aitken, M., \& MackINTOSH, N. J. (1994). Latent inhibition, context specificity, and context familiarity. Quarterly Journal of Experimental Psychology, 47B, 387-400.

Miller, R. R., Kasprow, W. J., \& Schachtman, T. R. (1986). Retrieval variability: Sources and consequences. American Journal of Psychology, 99, 145-218.

MiLleR, R. R., \& MATZEL, L. D. (1988). The comparator hypothesis: A response rule for the expression of associations. In G. H. Bower \& $\mathrm{H}$. Gordon (Eds.), The psychology of learning and motivation: Advances in research and theory (Vol. 22, pp. 51-92). San Diego: Academic Press.

Moran, P. M., Fischer, T. R., Hitchcock, J. M., \& Moser, P. C. (1996). Effects of clozapine on latent inhibition in the rat. Behavioural Pharmacology, 7, 42-48.

Moser, P. C., HitchCock, J. M., Lister, S., \& Moran, P. M. (2000). The pharmacology of latent inhibition as an animal model of schizophrenia. Brain Research Reviews, 33, 275-307.

Musen, G., \& Treisman, A. (1990). Implicit and explicit memory for visual patterns. Journal of Experimental Psychology: Learning, Memory, \& Cognition, 16, 127-137.

MUSSER, W. S., \& AKIL, M. (1996). Clozapine as a treatment for psychosis in Parkinson's disease: A review. Journal of Neuropsychiatry \& Clinical Neurosciences, 8 , 1-9.

NAKAYAMA, K. (1990). The iconic bottleneck and the tenuous link between early visual processing and perception. In C. Blakemore (Ed.), Vision: Coding and efficiency (pp. 411-422). Cambridge: Cambridge University Press.

Nuechterlein, K. H. (1977). Reaction time and attention in schizophrenia: A critical evaluation of the data and theories. Schizophrenia Bulletin, 3, 373-428.

NuECHTERLEIN, K. H., \& DAwson, M. E. (1984). Information processing and attentional functioning in the developmental course of schizophrenic disorders. Schizophrenia Bulletin, 10, 160-203.

Peacock, L., Solgaard, T., Lublin, H., \& Gerlach, J. (1996). Clozapine versus typical antipsychotics: A retro- and prospective study of extrapyramidal side effects. Psychopharmacology, 124, 188-196.

Pearce, J. M., \& Hall, G. (1980). A model of Pavlovian learning: Variations in the effectiveness of conditioned but not of unconditioned stimuli. Psychological Review, 87, 532-553.

Peters, S. L., Gray, J. A., \& JosePH, M. H. (1991). Pre-weaning nonhandling of rats disrupts latent inhibition in males, and results in persisting sex- and area-dependent increases in dopamine and serotonin turnover. Behavioural Pharmacology, 2, 215-223.

Pohjalainen, T., Rinne, J. O., Nagren, K., Syvalahti, E., \& HiETAla, J. (1998). Sex differences in the striatal dopamine $\mathrm{D}_{2}$ receptor binding characteristics in vivo. American Journal of Psychiatry, 155, 768-773.

PomerantZ, J. (1981). Perceptual organization in information processing. In M. Kubovy \& J. Pomerantz (Eds.), Perceptual organization (pp. 141-180). Hillsdale, NJ: Erlbaum.

RAINE, A. (1991). The SPQ: A scale for the assessment of schizotypal personality based on DSM-III-R criteria. Schizophrenia Bulletin, 17, 555-564.

RAINE, A. (1992). Sex differences in schizotypal personality in a nonclinical population. Journal of Abnormal Psychology, 101, 361-364. 
Rascle, C., Mazas, O., Vaiva, G., Tournant, M., Raybois, O., GoudeMAND, N., \& THOMAS, P. (2001). Clinical features of latent inhibition in schizophrenia. Schizophrenia Research, 51, 149-161.

Reicher, G. M., Snyder, C. R. R., \& Richards, J. T. (1976). Familiarity of background characters in visual scanning. Journal of Experimental Psychology: Human Perception \& Performance, 2, 522-530.

REISS, S., \& WAGNER, A. R. (1972). CS habituation produces a "latent inhibition effect" but no active "conditioned inhibition." Learning \& Motivation, 3, 237-245.

RESCORLA, R. A. (1971). Summation and retardation tests of latent inhibition. Journal of Comparative \& Physiological Psychology, 75, 77-81.

RESCORLA, R. A. (2002). Savings tests: Separating differences in rate of learning from differences in initial levels. Journal of Experimental Psychology: Animal Behavior Processes, 28, 369-377.

REYNOLDS, C. R., \& RichMOND, B. O. (1985). Revised children's manifest anxiety scale. Los Angeles: Western Psychological Service.

Richards, J. T., \& ReIcher, G. M. (1978). The effect of background familiarity in visual search: An analysis of underlying factors. Perception \& Psychophysics, 23, 499-505.

Rock, I., \& GuTMAN, D. (1981). The effect of inattention on form perception. Journal of Experimental Psychology: Human Perception \& Performance, 7, 275-285.

ROTH, R. H., \& ELSWORTH, J. D. (1995). Biochemical pharmacology of midbrain dopamine neurons. In F. E. Bloom \& D. J. Kupfer (Eds.), Psychopharmacology: The fourth generation of progress (pp. 227243). New York: Raven.

Salzman, A., Hadar, U., Korczyn, A., \& Lubow, R. E. (1994). Latent inhibition in Parkinson patients and elderly subjects. Unpublished manuscript.

Schatz, J. (1998). Cognitive processing efficiency in schizophrenia: Generalized vs. domain specific deficits. Schizophrenia Research, 30, 41-49.

SCHNEIDER, W., \& SHIFFrin, R. M. (1977). Controlled and automatic human information processing: Detection, search and attention. Psychological Review, 84, 1-66.

Schugens, M. M., TopKA, H. R., \& Daum, I. (1999). Eyeblink conditioning in neurological patients with motor impairments. In D. S. Woodruff-Pak \& J. Steinmetz (Eds.), Eyeblink classical conditioning: Human (pp. 191-204). New York: Kluwer.

Shadach, E., Feldon, J., \& WeINer, I. (1999). Clozapine-induced potentiation of latent inhibition is due to its action in the conditioning stage: Implications for the mechanisms of action of antipsychotic drugs. International Journal of Neuropsychology, 2, 283-291.

Shalev, U., Feldon, J., \& WeINER, I. (1998). Gender- and age-dependent differences in latent inhibition following pre-weaning non-handling: Implications for a neurodevelopmental animal model of schizophrenia. International Journal of Developmental Neuroscience, 16, 279288.

Shalev, U., \& Weiner, I. (2001). Gender-dependent differences in latent inhibition following prenatal stress and corticosterone administration. Behavioural Brain Research, 126, 57-63.

Shen, J., \& REINGOLD, E. M. (2001). Visual search asymmetry: The influence of stimulus familiarity and low-level features. Perception \& Psychophysics, 63, 464-475.

SHIFFRIN, R. M., \& SCHNEIDER, W. (1977). Controlled and automatic human information processing: II. Perceptual learning, automatic attending, and a general theory. Psychological Bulletin, 84, 127-189.

Silverstein, S. M., Kovacs, I., Corry, R., \& Valone, C. (2000). Perceptual organization, the disorganization syndrome, and context processing in chronic schizophrenia. Schizophrenia Research, 43, 11-20.

Sireteanu, R., \& Rettenbach, R. (2000). Perceptual learning in visual search generalizes over tasks, locations, and eyes. Vision Research, 40, 2925-2949.

SiTSKOORN, M. M., SALDEN, M., \& KAHN, R. S. (2001). Latent inhibition in first-episode patients with schizophrenia. Schizophrenia Research, 49, 145-146.

SpIElberger, C. D., Gorsuch, R. L., \& Lushene, R. E. (1970). Manual for the State-Trait Anxiety Inventory (Self-Evaluation Questionnaire). Palo Alto, CA: Consulting Psychologists Press.

SPRING, B. J., \& ZubIN, J. (1978). Attention and information-processing as indicators of vulnerability to schizophrenic episodes. Journal of Psychiatric Research, 14, 289-301.
StefFy, R. A., \& Waldman, I. (1993). Schizophrenics' reaction time: North star or shooting star? In R. L. Cromwell \& C. R. Snyder (Eds.), Schizophrenia: Origins, processes, treatment, and outcome (pp. 111134). New York: Oxford University Press.

Swerdlow, N. R., Braff, D. L., Hartston, H., Perry, W., \& Geyer, M. A. (1996). Latent inhibition in schizophrenia. Schizophrenia Research, 20, 91-103.

Swerdlow, N. R., Hartston, H. J., \& Hartman, P. L. (1999). Enhanced visual latent inhibition in obsessive-compulsive disorder. $\mathrm{Bi}$ ological Psychiatry, 45, 482-488.

Swerdlow, N. R., Magulac, M., Filion, D., \& Zinner, S. (1996). Visuospatial priming and latent inhibition in children and adults with Tourette's disorder. Neuropsychology, 10, 485-494.

Swerdlow, N. R., Stephany, N., Wasserman, L. C., Talledo, J., Sharp, R., \& AUERBACH, P. P. (2003). Dopamine agonists disrupt visual latent inhibition in normal males using a within-subject paradigm. Psychopharmacology, 169, 314-320.

Thornton, J. C., Dawe, S., Lee, C., Frangou, S., Gray, N. S., RusSELl, M. A., \& Gray, J. A. (1996). Effects of nicotine on latent inhibition in human beings. Psychopharmacology, 127, 164-173.

Treisman, A. [M.] (1993). The perception of features and objects. In A. D. Baddeley \& L. Weiskrantz (Eds.), Attention: Selection, awareness, and control. A tribute to Donald Broadbent (pp. 5-35). Oxford: Oxford University Press, Clarendon Press.

Treisman, A. M., \& Gelade, G. (1980). Feature integration theory of attention. Cognitive Psychology, 12, 97-136.

Tsakanikos, E., \& ReED, P. (2003). Visuo-spatial processing and dimensions of schizotypy: Figure-ground segregation as a function of psychotic-like features. Personality \& Individual Differences, $\mathbf{3 5}$, 703-712.

TsAKANIKOS, E., Sverdrup-Thygenson, L., \& ReEd, P. (2003). Latent inhibition and psychosis-proneness: Visual search as a function of pre-exposure to the target and schizotypy level. Personality \& Individual Differences, 34, 575-589.

UhlhaAs, P. J., Silverstein, S. M., Phillips, W. A., \& Lovell, P. G. (2004). Evidence for impaired visual context processing in schizotypy with thought disorder. Schizophrenia Research, 68, 249-260.

VAith, D., LipP, O. V., BAuer, U., Schuler, G., STARK, R., ZimMERMAN, M., \& KIRSCH, P. (2002). Latent inhibition and schizophrenia: Pavlovian conditioning of autonomic responses. Schizophrenia Research, 55, 147-158.

Vinogradov, S., PoOle, J. H., Willis-Shore, J., Ober, B. A., \& SheNAUT, G. K. (1998). Slower and more variable reaction times in schizophrenia: What do they signify? Schizophrenia Research, 32, 183-190.

Vollema, M. G., \& VAN DEN BosCH, R. J. (1995). The multidimensionality of schizotypy. Schizophrenia Bulletin, 21, 19-31.

WAGNER, A. R. (1981). SOP: A model of automatic memory processing in animal behavior. In N. E. Spear \& R. R. Miller (Eds.), Information processing in animals: Memory mechanisms (pp. 5-47). Hillsdale, NJ: Erlbaum.

Wang, Q., CaVAnagh, P., \& GReEN, M. (1994). Familiarity and pop-out in visual search. Perception \& Psychophysics, 56, 495-500.

WeINER, I. (2003). The "two-headed" latent inhibition model of schizophrenia: Modeling positive and negative symptoms and their treatment. Psychopharmacology, 169, 257-297.

WEINER, I., \& FELDON, J. (1997). The switching model of latent inhibition: An update of neural substrates. Behavioural Brain Research, 88, 11-25.

Weiner, I., Feldon, J., \& Katz, Y. (1987). Facilitation of the expression but not the acquisition of latent inhibition by haloperidol in rats. Pharmacology Biochemistry \& Behavior, 26, 241-246.

WEINER, I., FeldON, J., \& Ziv-HARRIS, D. (1987). Early handling and latent inhibition in the conditioned suppression paradigm. Developmental Psychobiology, 20, 233-240.

WEINER, I., LUBOW, R. E., \& FELDON, J. (1984). Abolition of the expression but not the acquisition of latent inhibition by chronic amphetamine in rats. Psychopharmacology, 83, 194-199.

Weiner, I., Schnabel, I., Lubow, R. E., \& Feldon, J. (1985). The effects of early handling on latent inhibition in male and female rats. Developmental Psychobiology, 18, 291-297.

WESTBROOK, F. R., Jones, M. L., BAILEY, G. K., \& Harris, J. A. (2000). Contextual control over conditioned responding in a latent inhibition 
paradigm. Journal of Experimental Psychology: Animal Behavior, 26, $157-17 \overline{3}$.

Williams, J. H., Wellman, N. A., Geaney, D. P., Cowen, P. J., FelDON, J., \& Rawlins, J. N. P. (1996). Antipsychotic drug effects in a model of schizophrenic attentional disorder: A randomized controlled trial of the effects of haloperidol on latent inhibition in healthy people. Biological Psychiatry, 40, 1135-1143.

Williams, J. H., Wellman, N. A., Geaney, D. P., Cowen, P. J., FelDON, J., \& RaWlins, J. N. P. (1998). Reduced latent inhibition in people with schizophrenia: An effect of psychosis or of its treatment. British Journal of Psychiatry, 172, 243-249.

Williams, J. H., Wellman, N. A., Geaney, D. P., Rawlins, J. N. P., FELDON, J., \& CowEN, P. J. (1997). Intravenous administration of haloperidol to healthy volunteers: Lack of subjective effects but clear objective effects. Journal of Psychopharmacology, 11, 247-252.

Wolfe, J. M. (1994). Guided Search 2.0: A revised model of visual search. Psychonomic Bulletin \& Review, 1, 202-238.

WuTHRICH, V., \& BATES, T. C. (2001). Schizotypy and latent inhibition: Non-linear linkage between psychometric and cognitive markers. Personality \& Individual Differences, 30, 783-798.

ZaLSTEIN-ORDA, N., \& LUBOW, R. E. (1995). Context control of negative transfer induced by preexposure to irrelevant stimuli: Latent inhibition in humans. Learning \& Motivation, 26, 11-28.

ZubIN, J., \& Spring, B. (1977). Vulnerability: A new view of schizophrenia. Journal of Abnormal Psychology, 86, 103-126.

\section{NOTES}

1. Although there are three target conditions that can be crossed with three distractor conditions $(3 \times 3)$, there are only seven viable types of test trial. If a test phase display had a target that had previously been a distractor in the preexposure phase and a distractor that had previously been a distractor, all 20 figures in the display would be the same (i.e., there would be no unique figure); the same homogeneous test phase display configuration would occur if the test phase distractor had previously been a target and the test phase target had also previously been a target.

2. Although the latter study can be discounted because of grossly unequal representations of males and females and the small number of female subjects, the remaining studies did not suffer from such problems.

3. LI studies with healthy human subjects frequently have a disproportionately large number of females, as compared with males (often two to one). Such a gender bias may result in an underestimate of the basic LI effect. In similar studies with schizophrenic patients, the maleto-female ratios typically are reversed.

4. The correspondence between dopamine agonists, such as amphetamine, that produce psychotic-like effects in humans and reduce LI and dopamine antagonist neuroleptics, such as haloperidol, that counteract effects of dopamine agonists and produce super-LI also can be found with atypical antipsychotic drugs, such as clozapine (e.g., Moran, Fischer, Hitchcock, \& Moser, 1996; Shadach, Feldon, \& Weiner, 1999).

5 . All of these studies used CRs as the dependent variable. LI schizophrenia experiments also have used electrodermal responding (Vaitl et al., 2002) and event-related potentials (Guterman, Josiassen, Bashore, Johnson, \& Lubow, 1996; Kathmann, von Recum, Haag, \& Engel, 2000), with basically similar results.

6. The difference in results may be due to the fact that Uhlhaas et al. (2003) selected subjects from the lower and upper 20th percentiles of schizotypy questionnaire scores, whereas Tsakanikos and Reed (2003) used an unselected group. The relatively weak effect of schizotypy level on LI reported by Lubow et al. (2001) also may be attributable to using subjects from the full range of schizotypy scores.

(Manuscript received April 7, 2004;

revision accepted for publication September 5, 2004.) 